\title{
WAVE-2 and its role in LRRK2 mediated Neuroinflammation
}

\author{
By
}

\author{
Jawaria Abdali
}

A thesis submitted to the Faculty of Graduate and Postdoctoral Affairs in partial fulfillment of the requirements for the degree of

Master of Science

in

Neuroscience

Carleton University

Ottawa, Ontario

(C) 2019

Jawaria Abdali 


\begin{abstract}
Neuroinflammation is involved in the pathogenesis of many neurodegenerative diseases, including Parkinson's Disease, primarily resulting from microglial activation. Microglia are the primary phagocytic cells of the central nervous system, and their activation play a significant role in neuroinflammation. Microglial activation and the changes in their morphological appearance depend on the actin cytoskeleton reorganization. WASP family Verprolin-homologous protein-2 (WAVE2), a member of Wiskott Aldrich's Syndrome Proteins, is a primary regulator of actin cytoskeleton. WAVE2 primarily expresses in immune cells and has an important role in cytoskeleton reorganization, which is a crucial process for cell motility and formation of various cellular processes. This study is aimed to test the effect of WAVE2 inhibition on inflammatory phenotype of BV-2 microglial cells. We have shown that lipopolysaccharides (LPS) stimulation significantly upregulates oxidative stress and nuclear factor kappa-B (NF-kB) signaling, and cause changes in appearance of BV-2 microglial cells. Knocking down WAVE2 with the help of adenoassociated virus vector does not block these outcomes. These data suggest that the inflammatory phenotype of microglial cells may not be primarily dependent on WAVE2 signaling.
\end{abstract}




\section{Acknowledgements}

I would like to sincerely extend my respect and thanks to all members of the Hayley lab, especially Teresa Fortin, our wonderful lab coordinator, who is always there to help. I am also in debt for the continuous support and guidance my seniors have provided me throughout my journey, specifically Zach Dwyer. Thank you, everyone, for being so kind and supportive.

I can't thank enough for my beloved husband, Osama Abdali for his never-ending care and support. You were with me when the times were smooth and also when it was quite rough during this journey. Thank you for keeping my motivation alive and always believing in me. I would like to dedicate my work to my children Osayd and Saad. Osayd was the reason I choose to pursue Neuroscience. Though you are not physically with me, your memories are alive in my heart. I miss you very much. My little bundle of joy, Saad, I am surprised how your tiny brain can absorb difficult neuroscience vocabularies. The way you discuss those with me like an expert always makes me smile. I am blessed to have you in my life.

I would also like to thank my committee members, Dr. Michael Hildebrand and Dr. Matthew Holahan for their continuous support and guidance. Finally, and most importantly, I would like to thank my supervisor Dr. Shawn Hayley, who has provided me with a wonderful learning experience. Thank you for believing in me and allowing me to be a part of your dynamic team. 


\section{Table of Contents}

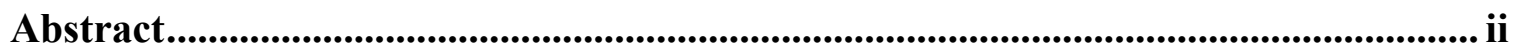

Acknowledgements ........................................................................................................................ iii

Table of Contents......................................................................iv

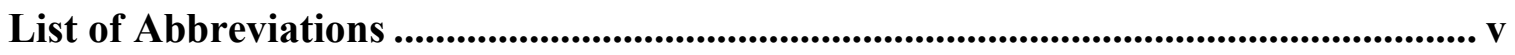

List of Figures................................................................................................................................. vi

Introduction....................................................................... 7

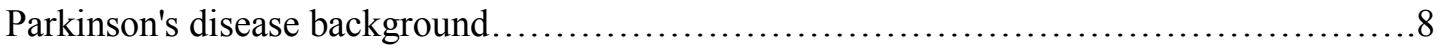

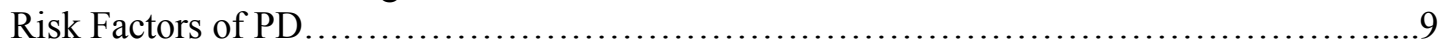

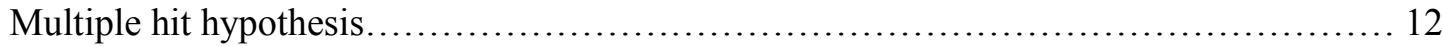

LRRK2 as a vulnerable factor in PD ............................................... 14

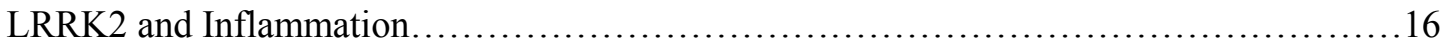

Microglia role in PD associated neuroinflammation................................... 17

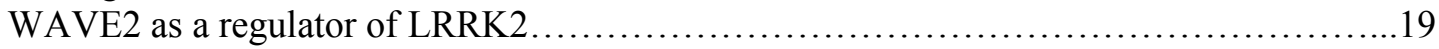

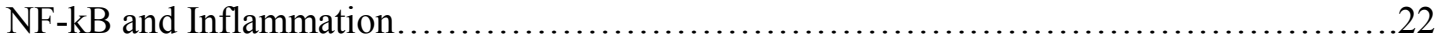

Research purpose and Hypothesis......................................... 24

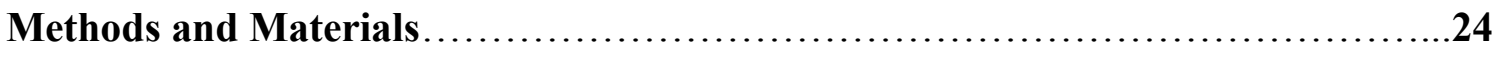

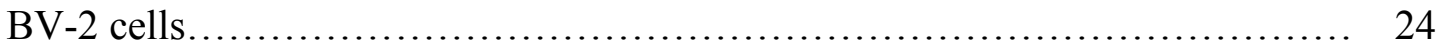

Study design........................................................... 27

Reagents............................................................... 31

Cell culture ............................................................. 31

Transfection of BV-2 cells................................................. 32

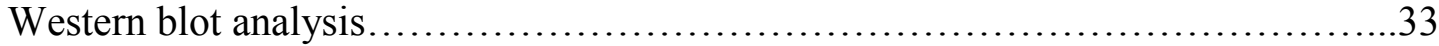

CellRox................................................................ 34

Immuno-Fluorescence staining for NF-kB ............................. 34

Morphology ........................................................... 35

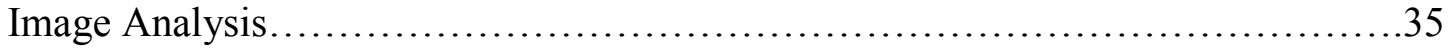

Statistical Analysis..................................................... 36

Results...................................................................................35

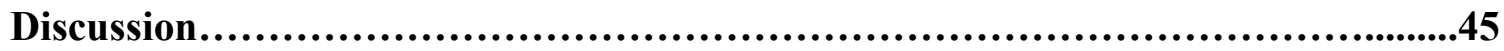

References.............................................................................48 


\section{List of Abbreviations}

PD

$\mathrm{SNpc}$

DA

SNCA

REM

LRRK2

VPS35

NGS

PARK-2

DJ-1

PINK-1

ROS

$\mathrm{OH}$

DNA

ROCO

GTPase

COR

LRR

mRNA

CNS

LPS

NF-kB

INF-y

$\mathrm{NO}$

NGF

TLR

PAMP

TNF- $\alpha$

IL- $1 \beta$

IL-6

WAVE

WASP

WRC

Arp2/3

Abi

Nap-1

HSPC-300

BMDMs
Parkinson's disease

substantia nigra pars compacta

dopamine

synuclein alpha

rapid eye movement

leucine-rich repeat kinase-2

vacuolar protein sorting 35

next-generation sequencing

Parkinson's-2

protein deglycase-1

PTEN-induced kinase-1

reactive oxygen species

hydroxyl

deoxy ribonucleic acid

Ras of complex

guanosine triphosphatase

C-terminus of

leucine-rich repeats

messenger ribonucleic acid

central nervous system

lipopolysaccharide

nuclear factor kappa-B

interferon-gamma

nitric oxide

nerve growth factor

toll-like receptor

pathogen-associated molecular pattern

tumor necrosis factor alpha

interleukin-1 betta

interleukin-6

WASP family Verprolin homologous protein

Wiskott Aldrich's syndrome protein

wave regulatory complex

actin regulatory protein $2 / 3$

Abelson interactor 1

nucleosome assembly protein 1

hematopoietic stem/progenitor cell protein 300

bone-marrow derived macrophages 


\section{List of Figures}

Figure 1. Schematic overview of Parkinson's Disease risk factors 11

Figure 2. Schematic representation of LRRK2 15

Figure 3. WASP as a regulator of actin nucleation 22

Figure 4. Study design and timeline for experiment 1

$\begin{array}{lll}\text { Figure 5. Study design and timeline for experiment } 2 & 27\end{array}$

Figure 6. Effect of LPS stimulation on BV-2 cells morphology 35

$\begin{array}{lll}\text { Figure 7. Effect of LPS on oxidative stress in BV-2 cells } & 37\end{array}$

Figure 8. Effect of LPS on NF-kB signaling in BV-2 cells 38

$\begin{array}{lll}\text { Figure } 9 & \text { Western blot result } & 39\end{array}$

Figure 10. WAVE2 knock-down effect on BV-2 microglial morphology 40

Figure 11. Effect of WAVE2 inhibition on oxidative stress 42

Figure 12. Effect of WAVE2 knockdown virus on NF-kB signaling 44 


\section{Introduction:}

\section{Parkinson's disease background:}

Parkinson's disease (PD) first described as “Shaking Palsy” by Dr. James Parkinson in 1817 , is second most common chronic and progressive neurodegenerative disease after Alzheimer's disease and the most common movement disorder (Mhyre et al., 2012). PD affects more than 10 million people worldwide and its prevalence increases with age, affecting $1 \%$ of the population older than 60 and approximately $4 \%$ at the age of 80 years (De Lau \& Breteler, 2006). However, only 4\% of all PD patients present with early onset of the disease, with the diagnosis before the age of 50 (Reeve, Simcox \& Turnbull, 2014). The neuropathological hallmarks of PD are the loss of dopamine (DA) producing neurons in the substantia nigra pars compacta (SNpc) of the midbrain, intracytoplasmic aggregations of alpha-synuclein protein (SNCA) in the form of Lewy bodies, as well as subsequent development of dystrophic striatal projections (Mhyre et al., 2012). Furthermore, neuroinflammation, mitochondrial dysfunction, oxidative stress and, excitotoxicity also plays a crucial role in the PD pathology (Kaur, Mehan \& Singh, 2018). Indeed, PD is a complex disease involving the interplay of multiple molecular mechanisms, rendering its study a challenge for researchers.

Clinically, PD presents with a wide range of motor and non-motor symptoms. Pillrolling resting tremors, postural instability, bradykinesia (slowness of movement) and rigidity are the four classic motor hallmarks of Parkinson's disease (Gelb, Oliver \& Gilman, 1999). The clinical diagnosis of PD is based on the presence of these cardinal motor symptoms, but in addition to these motor symptoms, patients with this devastating disorder experience a variety of non-motor symptoms including gastrointestinal and 
autonomic dysfunction (e.g. constipation, postural hypotension, urinary and erectile problem), sleep disorder (e.g. REM sleep behavioral disorder) and olfactory dysfunction (Lill, 2016). The presence of anxiety, depression, memory problem, and cognitive decline are also common psychiatric symptoms associated with PD (Shulman et al., 2001 \& 2002). The non-motor symptoms associated with PD most likely occur as a result of neuronal degeneration in the brainstem, cerebral cortex and the thalamus (DeLong and Wichmann, 2007). Interestingly, the non-motor signs and symptoms of PD are known to be present up to 10 years before the onset of the classic motor symptoms (Schrag et al., 2015). The complex pattern of symptoms observed in PD significantly influence the patient's quality of life, as these features impact nearly all daily activities.

The current treatment for PD only provides symptomatic relief. Unfortunately, the treatment usually initiated only after the onset of motor symptoms, and at that point in time more than $80 \%$ of dopaminergic neurons have already been lost (Cheng, Ulane \& Burke, 2010). Despite the recent advancement in clinical research, there is no disease-modifying treatment available for PD that could alter the underlying neurodegenerative process. The first-line therapy of PD involves replacing the dopamine that is lost as the neurons in SNpc degenerate, and involves the administration of a dopamine precursor, Levodopa (Fan, Lin, Liu \& Yeh, 2017). Levodopa is the most potent drug for controlling the motor symptoms of PD and available as a combination with Carbidopa, a dopamine decarboxylase inhibitor, to prevent peripheral degradation of Levodopa (Fan et al., 2017). 


\section{Risk Factors for Parkinson's disease:}

PD is a complex multifactorial neurodegenerative disorder. It is predominantly a sporadic disease, with the age being the most important risk factor; however, it is familial in approximately $10 \%$ of the cases (Lesage \& Brice, 2012). The exact mechanism underlying the loss of dopaminergic neurons in PD is not very clear, but research in the last twenty years has shown that indeed genetics has an important role in disease development (Lill, 2016). Monogenic form of PD caused by highly penetrant rare mutations, present in approximately $5-10 \%$ of all PD patients (Lill, 2016). Both autosomal dominant and autosomal recessive forms of the monogenetic disease have been identified. Mutation in SNCA (synuclein alpha) gene was the first autosomal-dominant PD mutation that was discovered two decades ago (Polymeropoulos et al., 1997). It is also a major component of Lewy bodies, a pathognomic feature of idiopathic PD (Spillantini et al., 1997). An important physiological role of alpha-synuclein in both the central and the autonomic nervous system is its involvement in the exocytosis of the presynaptic vesicles (a process of moving materials from within the cell to the exterior of the cell), and neurotransmitter release (Bendor, Logan \& Edwards, 2013).

Another autosomal- dominant mutation that has been strongly linked to PD, is the mutation in the LRRK2 gene (leucine-rich repeat kinase 2) and is identified as the most frequent autosomal-dominant mutation in PD (Zimprich et al., 2004). LRRK2 gene is located on chromosomes 12 and encodes LRRK2 protein which is a multi-domain protein present in the cytoplasm (Mhyre, Boyd, Hamill \& Maguire-Zeiss, 2012). Advancement in genetic research and the development of whole-exome next-generation sequencing (NGS) have led to the discovery of another dominant mutation linked to PD: VPS35 (encoding 
vacuolar protein sorting 35 retromer complex component) mutation is the latest PD gene, independently identified by NGS technology, by two different groups, in an Austrian family with 16 affected individuals with PD (Zimprich et al., 2011); and in Swiss kindred (Vilarino-Guel et al., 2011). Autosomal recessive mutations are relatively rare in PD, but are associated with early-onset of PD, and include Parkin (PARK2), DJ-1 (PARK7) and PINK1 (PTEN induced putative kinase 1); (Kitada et al.1998, Bonifati et al., 2003 Valente et al., 2004). Among these recessive mutations, the most common is Parkin, which accounts for $8.6 \%$ of early-onset PD, followed by PINK1(3.7\%) and DJ1(0.4); (Kilarski, Pearson, Newsway et. al., 2012).

In addition to genetics, a wide range of environmental factors present as risk factors for Parkinson's disease. It is a well-known fact that in most genetically complex diseases, the outcome is the result of an interplay between an individual's genetic make-up and environmental or lifestyle influences. Environmental factors that have shown to contribute to PD pathology, include exposure to toxins such as heavy metals (e.g. manganese, iron), pesticides, viral or bacterial infection (Gutman et al., 1970; Bus \& Gibson, 1984; Dick et al., 2007: Tanner et al., 2011). In 2011, a study by NIEHS (National Institute of Environmental Health sciences) in California USA, showed a link between PD and the use of two occupational pesticides, rotenone, and paraquat (Tanner et al., 2011). These pesticides have been extensively used to model PD in the laboratory as they result in the loss of dopaminergic neurons in the SNpc (Cichetti et al., 2009; Tanner et al., 2011). Rotenone induces mitochondrial respiratory dysfunction, by inhibiting complex1(Henchcliffe \& Beal, 2008). Paraquat, a widely used herbicide, induces neuronal damage by increased oxidative stress and formation of reactive oxygen species ROS (McCarthy et 
al., 2004). Oxidative stress occurs due to an imbalance between the production of ROS and the cellular antioxidant activity (Dias, Junn and Mouradian, 2013). Dopaminergic neurons are particularly vulnerable to oxidative stress because of the presence of ROS-generating enzymes such as tyrosine hydroxylase and monoamine oxidase (Dias et al., 2013). ROS are free radicals and their formation require activation of molecular oxygen (Dias et al., 2013). The examples of ROS include the superoxide, hydroxyl radical (OH) and hydrogen peroxide (Dias et al., 2013).

PD is caused by the combined action- and likely interaction- of genetic variants (potentially hundreds of DNA sequence variants), environmental exposure of toxin and probably epigenetic factors (Lill, 2016).

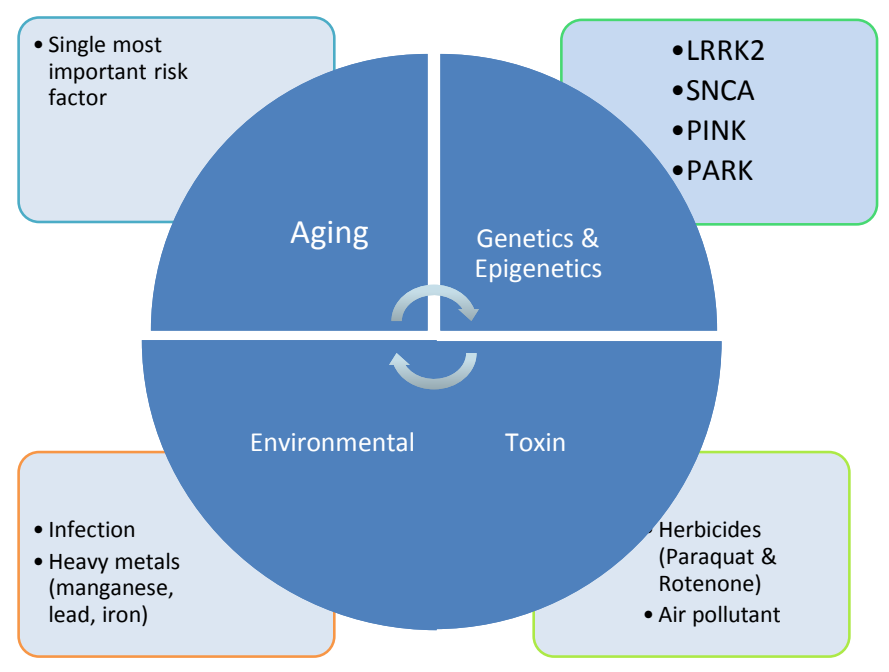

Figure 1: Schematic overview of the PD risk factors 


\section{Multiple hit hypothesis:}

The etiology and pathogenesis of PD are very complex. Though genetics play an important role, the low penetrance of many genes such as LRRK2, SNCA, etc. suggests that there must be an interaction between different causative factors. The term "multiple hits" has been referred frequently when describing PD etiology, which suggest that numerous factors such as aging, genetic mutations, vulnerability of dopaminergic neurons to oxidative stress, mitochondrial dysfunction, inhibition of neuroprotective response, and environmental toxin exposure, all contribute collectively for the onset for dopaminergic neuronal death in SNpc (Sulzer, 2007; Ross et al., 2008; Driver et al., 2009; and Lee et al., 2012). There are certain environmental factors also exist which seem to have a protective effect on PD risks, such as exercise, caffeine consumption, smoking, and alcohol consumption (Van der Mark et al, 2014; Zhang et al., 2014 and Saaksjarvi et al, 2014). All these factors signify that indeed environment does play an important role in the development of this devastating disease. The massive loss of SN dopaminergic neurons in PD probably results from the combination of certain "primary hits" which lead to SN neuronal stress and by "secondary hits" which result from loss of protective pathways and thereby induce neuronal damage and death (Sulzer,2007). Oxidative stress is known to be the primary contributing factor in many neurodegenerative diseases including PD (Kim et al., 2015). In post-mortem PD brains, the presence of increased lipid peroxidation and elevated iron level suggest the important role of oxidative stress in PD pathogenesis (Olanow and Tatton, 1999). The structure and function of substantia nigra dopaminergic neurons and the metabolism of dopamine itself, increase the vulnerability of these cells to oxidative stress (Sulzer, 2003). Neurodegenerative diseases typically affect projection 
neurons with long unmyelinated axons and surprisingly, neurons with alpha-synuclein aggregations in PD have long and poorly myelinated or unmyelinated axonal projections (Sulzer, 2003). Furthermore, the reduced trophic support and the deficit in the antiapoptotic buffering capacity of SNpc dopamine neurons further contribute to the vulnerability of these neurons (Nagatsu et al., 2000; Lev et al., 2003).

Mitochondrial dysfunction in the dopaminergic neurons is also one of the contributing factors in PD etiology and its involvement is suggested by the fact that the toxins rotenone in PD animal model, results in damage of DA neurons through the inhibition of the complex-1 of the mitochondrial electron transport chain (Dauer \& Prezedborski, 2003). Mitochondrial complex 1 enzyme activity is found to be reduced in PD (Dauer \& Prezedborski, 2003). Besides genetics, oxidative stress and mitochondrial dysfunction, another important mechanism involved in PD pathogenesis, is the presence of chronic inflammation. Neuroinflammation has been recognized in many neurodegenerative diseases including PD (Sulzer, 2003). Many studies have reported the consistent finding of enhanced activation of the neuroinflammatory system in the PD brain, as well as in animal model (Nagatsu and Sawada, 2005; McGeer and McGeer, 2008, Tufecki et al., 2011). Konstantin Tretiaskoff, a Russian neuropathologist had first noticed inflammation in PD nearly a century ago (Sulzer,2003). This neuroinflammation thought to be caused by the release of the toxic molecule from activated glial cells, might have an important role in the process of neurodegeneration as there was evidence of glial response in the areas of the brain where neurodegenerative changes were found (Przedborski, 2010). The glial reaction in PD mainly consists of microglia and astrocytes (Przedborski, 2010). 


\section{LRRK2 as a vulnerable factor in PD:}

Leucine-rich repeat kinase 2 (LRRK2) belongs to the ROCO (Ras Of Complex) family of proteins (Esteves, Swerdlow and Cardoso, 2014). An important characteristic of this family of proteins is that it contains both a small GTPase and a kinase domain, as well as a C-terminus of Ras Complex (COR) domain (Esteves et al., 2014). Similarly, LRRK2 protein consists of multiple well-defined domains, including a ROC domain, a GTPase domain, COR domain and a serine-threonine kinase domain (Russo et al., 2014). It also has many protein-protein interaction domains e.g. the leucine-rich repeat domain (LRR), WD 40 domain, ankyrin and an armadillo repeat domain (Esteves et al., 2014). LRRK2 is widely expressed in brain and peripheral tissues. Both the LRRK2 mRNA and protein, have been detected in specific regions of the brain including cortex, striatum, hippocampus and SNpc (Han, Lacoviti, Katano \& Hattori, 2008). LRRK2 also expressed in circulating immune cells, and the presence of any microbial structures and viral particles enhanced this expression (Esteves et al., 2014). LRRK2 is very diverse in its functionality and has been involved in various cellular functions such as cytoskeletal maintenance, neurite outgrowth, vesicle trafficking, autophagic protein degradation, mitochondrial dysfunction and inflammatory signaling (Rideout and Stefanis, 2014).

Mutations in the LRRK2 gene have been associated with approximately $13 \%$ of all familial and 1 to $2 \%$ of all sporadic PD (Marin, 2006). Interestingly, there are no clinical and pathological differences between the LRRK2 associated Parkinson's and sporadic PD, indicates the possibility of an overlapping pathway (Russo et al., 2014). At least, six different highly penetrant pathogenic mutations have been identified in LRRK2 gene, among them, Glycine20 to Serine19 or G2019S is by far the most common LRRK2 
mutation (Healy et al., 2008). It has been known that the penetrance of LRRK2 mutation is age-related in PD and depends on gene-environment interaction and the mutant LRRK2 toxicity (Martin et al., 2014). For mutant form of LRRK2 protein to trigger cell death, an intact kinase and GTPase activity are very essential, but the exact mechanism has not yet been established (Rideout \& Stefanis, 2014). Mutant LRRK2 is associated with increased in kinase activity, and there is evidence present which suggests the LRRK2 toxicity is kinase-dependent (Martin et al., 2014).

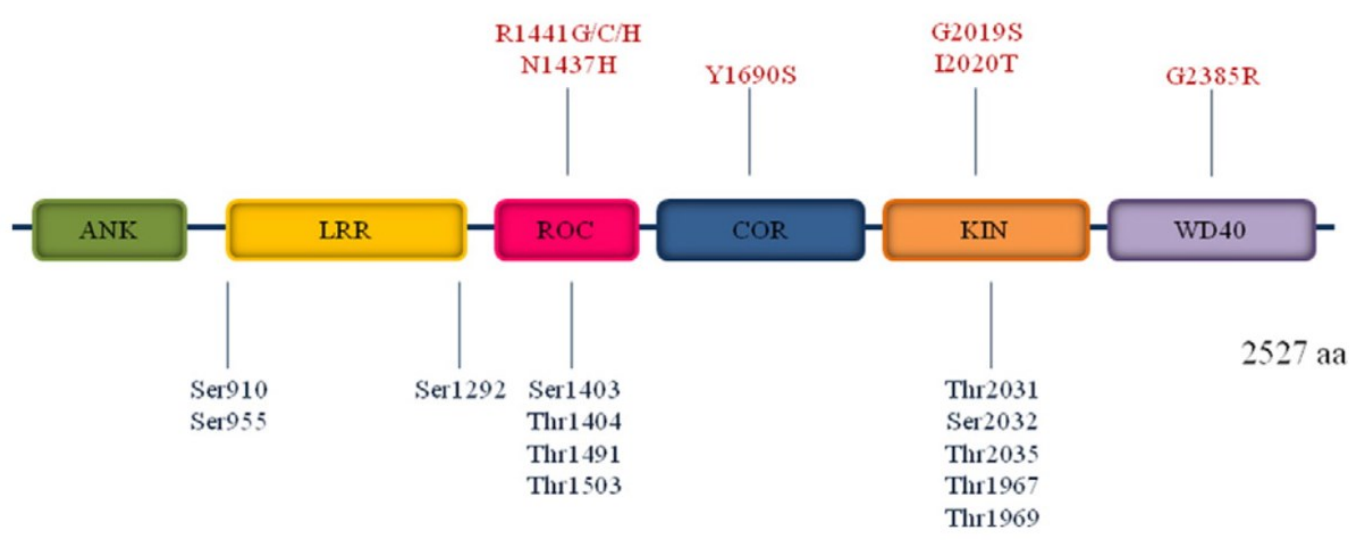

A.R. Esteves et al./ Experimental Neurology 261 (2014) 206-216

Figure 2: Schematic representation of LRRK2. The central region contains a GTPase domain also called ROC, a COR domain of the unknown function and a kinase domain. PD pathogenic mutations are depicted in red on top and phosphorylation sites are depicted in blue blow. 


\section{LRRK2 and inflammation:}

Although the integrity and proper functioning of the central nervous system (CNS) require a well-controlled inflammatory reaction, excessive or prolonged inflammatory activity can be very damaging to the neurons. In accordance with the complexity of PD pathogenesis, evidence has suggested that a common inflammatory mechanism is involved in the pathogenesis of PD (Russo et al., 2011). Studies have shown that LRRK2 is involved in modulating neuroinflammation in response to different pathological stimuli (Russo, Bubacco \& Greggio, 2014). Interestingly, besides being associated with both familial and sporadic PD, mutations in the LRRK2 gene have been also linked to other inflammatory diseases such as Crohn's disease and Leprosy (Zhang et al., 2009, Umeno et al., 2011). LRRK2 mRNA and protein expression are found to be elevated in the immune cells, specifically in microglia and astrocytes from the human and rodent brain (Moehle et al., 2012). Moehle and colleagues also observed that after lipopolysaccharide (LPS)-induced inflammation, expression of LRRK2 protein found to be elevated in mouse microglial cells of SNpc and striatum (Moehle et al., 2012). LPS is a bacterial endotoxin, found in the outer membrane of gram-negative bacteria and induces a strong immune response and promotes the release of pro-inflammatory cytokines (Rietschel et al., 1994). It is also known to induce production of superoxide (ROS) and stimulation of transcription factor e.g. nuclear factor kappa-B (NF-kB) from the immune cells (Rietschel et al., 1994).

In vitro studies also reported having an increased LRRK2 protein expression in microglial cell culture, upon stimulation with LPS or INF-y (Gillardon, Schmid \& Draheim, 2012). Reduced levels of LPS-stimulated inflammatory mediators were recorded in microglia that had down-regulated LRRK2 (Kim et al., 2012, Moehle et al., 2012). 
Gillardon and colleagues have reported that microglia in the LRRK2 R1441G knock-in mice when stimulated with LPS, showed an increased expression of pro-inflammatory cytokines and decreased expression of anti-inflammatory cytokines (Gillardon et al., 2012). These studies have strongly supported the role of LRRK2 as a modulator of inflammation in the pathogenesis of PD (Gillardon et al., 2012; Kim et al., 2012; Moehle et al., 2012).

\section{Microglia's role in PD associated neuroinflammation:}

Microglia are the primary resident phagocytic cells of the innate immune system of the brain and are considered to be the key players during neuroinflammation (Russo et al., 2011). Although the role of inflammation as a causative factor or as a secondary effect in the pathogenesis of PD is still in debate. A growing number of studies have supported that the immune system is most likely involved in the etiology and also contribute to the disease progression (Gao \& Hong, 2008; Hirsch \& Hunot, 2009; Herrero et al., 2015). Microglia acts like a double-edged sword, as they could be neuroprotective or neurotoxic depend on their duration of activation. Chronic activation of microglia as evident in many neurodegenerative diseases such as Alzheimer's disease and PD, cause neuronal damage by releasing many cytotoxic chemicals e.g. reactive oxygen species (ROS), nitric oxide (NO), proinflammatory cytokines, nerve growth factor (NGF), and chemotactic cytokines

(Xiao-jing et al., 2014). As primary immune cells of the CNS, they are the first line of defense against microbial pathogens and also play a crucial role in neurons development and maintenance (Xiao-jing et al., 2014). 
Microglial cells are highly dynamic and exhibit functional plasticity, they continually survey the brain parenchyma and become activated upon detection of any abnormal changes in the surrounding tissue and switch from the resting ramified form into an active amoeboid form (Russo et al., 2011). This morphological transformation of microglia is possible as a result of a series of molecular and cellular changes (Graeber, 2010). In the CNS, microglia present in two distinct forms, resting or ramified and activated form. The ramified form is the resting or inactive state of microglia in which they mainly perform surveillance (Stansley, Post \& Hensley, 2012). There are two distinct activated states of microglia in the brain, M1, and M2 (Stansley et al., 2012). The M1 state of microglia refers to the classic activation of microglia in response to stimuli such as LPS or interferon (INF- §), which causes the release of pro-inflammatory cytokines and results in neuronal injury (Stansley et al., 2012). While the M2 amoeboid state of microglia is antiinflammatory as it not only blocks the secretion of pro-inflammatory cytokines but also stimulates the release of neurotrophic factor and involves in the tissue repair (Stansley et al., 2012).

Microglia detect intruding microbial organisms and tissue damage with the help of a broad range of pattern-recognition receptors from the toll-like receptor family (TLR family) (Lee \& Lee, 2002). Since these TLRs are widely expressed in microglia, they easily recognize pathogen-associated molecular patterns (PAMP) on the surface of the microbial organism and regulate gene expression through the activation of different intracellular signals (Akira et al., 2006). Studies have suggested that TLRs are involved in many different CNS diseases, from infection and trauma to neurodegenerative and autoimmune diseases (Xiao-jing et al., 2014). In 2003, Lehnardt and team found out the critical role of 
TLR4 in activated microglia to induce neuronal injury. When LPS stimulated microglia were cultured together with neurons from TLR4 KO mice, the neuronal injury was blocked (Lehnardt et al., 2003). Activated microglia secrete multiple inflammatory mediators and migrate to the affected area to phagocyte dead cells or aggregated protein (Neumann, Kotter \& Franklin, 2009). It is interesting to know that multiple pro-inflammatory cytokines such as tumor necrosis factor (TNF- $\boldsymbol{\alpha})$, interferon- $\gamma$, interleukin (IL-1 $\beta$ ) and IL6 have been found in elevated level not only in CSF but also in the striatum and SNpc of both the experimental animal model and also in the postmortem brains from patient with PD (Gao H \& Hong J, 2008).

\section{WAVE2 as a regulator of LRRK2:}

Besides being an important modulator of inflammation in PD pathogenesis, studies have shown that LRRK2 also regulates the organization of the actin cytoskeleton and microtubule assembly, and this role of LRRK2 might be implicated in the neuronal damage underlying PD (Russo et al., 2012). The actin cytoskeleton plays an essential role in cell morphology and motility. Cytoskeletal remodeling is a very critical process for microglia and brain macrophage functioning and this process in activated microglia is regulated by microtubule and actin cytoskeleton (Caesar et al., 2013). The role of LRRK2 as a modulator of actin cytoskeleton organization is supported by the fact that in LRRK2 knockdown or LRRK2 inhibitor-treated microglial cells, the inflammatory stimuli failed to induce any significant changes of the process extension and cytoskeleton remodeling (Moehle et al., 2012). Another study by Caesar and colleagues demonstrated that human LRRK2 G2019S and mouse LRRK2 knockout fibroblast showed a difference in cell migration in culture (Caesar et al., 2013). The results showed human LRRK2 G2019S fibroblast migrating 
faster, and LRRK2 knockout fibroblast migrating slower as compared to the control cells (Caesar et al., 2013). Since G2019S mutation is associated with an increased in LRRK2 kinase activity, it appears that the kinase activity is essential for microglial motility and cytoskeleton remodeling (Russo et al., 2014). LRRK2 also involve in the microglial phagocytosis (Marker et al., 2012). Markel and colleagues reported that the microglial phagocytosis of fluorescent beads after an inflammatory stimulus is decreased with the use of LRRK2 inhibitor (Marker et al., 2012). These studies have suggested that LRRK2 regulates microglial activation, its migration and, phagocytosis, however, the exact mechanism underlying these processes is still ongoing research (Marker et al., 2012; Moehle et al., 2012; Russo et al., 2014).

Previous studies have identified Scar/WAVE (Wiskott-Aldrich syndrome proteinfamily verprolin) proteins as a potential genetic interactor of LRRK2 (Marcogliese et al., 2017; Kim et al., 2018). A recent study has demonstrated that LRRK2 modulates the phagocytic response of myeloid cell by specific modulation of actin-cytoskeletal regulator WAVE2 (Kim et al., 2018). They have shown that the WAVE2 mediated phagocytic response has been enhanced in macrophage and microglia derived from LRRK2 G2019S PD patients and mice, respectively. This study has also demonstrated that WAVE2 regulates the LRRK2 G2019S-induced dopaminergic neuronal death (Kim et al., 2018).

The Wiskott-Aldrich syndrome protein (WASP) and WASP-family verprolinhomologous protein (WAVE) have known to be the fundamental regulator of actin cytoskeleton (Pollitt \& Insall, 2009; Reicher et al., 2012; Joseph et al., 2017). The first human WAVE protein was identified independently by two groups as a WASP-like molecule and was named WAVE and SCAR respectively (Miki, Suetsugu \& Takenawa, 
1998; Machesky \& Insall, 1998). WAVE proteins exist as a part of a pentameric protein complex called "WAVE Regulatory Complex or WRC" (Pollitt \& Insall, 2009). This complex consists of two WASP proteins; hematopoietic WASP and neural or N-WASP and three WAVE proteins; WAVE1, WAVE2, and WAVE3 (Reicher et al., 2012). All five WAVE family proteins are required for the stability of WRC (Noah Joseph et al., 2017). These proteins induce rapid actin polymerization through its activation of actin regulatory proteins, Arp2/3 complex (Kurisu \& Takenawa, 2009). Figure 3. Arp2/3 complex act as a template for the formation of new actin filaments (Huang et al., 2006). This process of forming new actin filaments is very critical for the formation of cellular processes essential for endocytosis and cell motility (Kurisu \& Takenawa, 2009). WASP family of proteins regulate the activation of the Arp2/3 complex (Takenawa and Miki, 2001). WASP proteins are also involved in numerous cellular functions such as the embryonic development, immune response, tissue repair and cell motility and migration (Joseph et al., 2017). WAVE1 and WAVE3 show enhanced expression in neuronal cells, also express moderately in hematopoietic cells, whereas WAVE2 primarily expressed in the hematopoietic cell lineage and in microglia (Kwang et al., 2018). WAVE2 protein itself is regulated by a protein complex consists of 4 proteins; PIR 121, Nap1, Abi and HSPC300 (Davidson and Insall, 2013). WAVE2 is a central regulator of F-actin polymerization (Pollitt and Insall., 2009). Interestingly, WAVE 2 deficiency is embryonically lethal, as WAVE2 deficient mice die at embryonic day 10 due to hemorrhage caused by aberrant platelets (Reicher et al., 2012). 


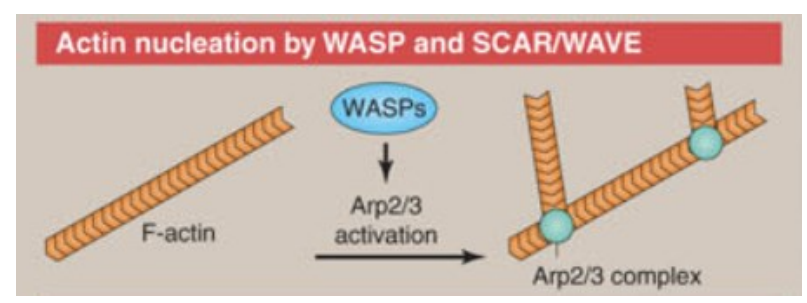

Figure 3: WASPs as a regulator of actin nucleation

(Modified from Pollitt and Insall, 2009, Journal of Cell Science, 122, 2575-2578)

\section{NF-kB and its role in Inflammation:}

Nuclear factor kappa-B (NF-kB) is a very important transcription factor and plays a critical role in the immune and inflammatory response (Sirinavasan and Lahiri, 2015). Once activated, NF-kB induces transcription of many pro-inflammatory genes and thereby regulates inflammation (Tak and Firestein, 2001). It mediates the synthesis of various inflammatory cytokines such as TNF-alpha, IL-1, IL-6, IL-8, and cyclooxygenase 2 (Cox2) (Aupperle et al., 1999). NF-kB present in an inactive form in the cytoplasm (Gilmore, 2006). It becomes highly activated at the inflammation site in different diseases such as inflammatory bowel diseases (IBD), arthritis, sepsis, and neurodegenerative diseases (Gilmore, 2006; Sirinavasan \& Lahiri, 2015). There are five proteins in NF-kB transcription family, NF-kB1(p50), NF-kB2(p52), Rel-A(p65), Rel-B and c-Rel (Tak and Firestein, 2001). Most of the proteins in this family can form homodimers and /or heterodimers. NF-kB present in the cytoplasm in the form of a complex with a protein called inhibitor of kappa-B (IkB), which prevents NF-kB activation in resting cells (Tak and Firestein, 2001). Phosphorylation of IkB is required for NF-kB activation and is mediated by the inhibitor of the kappa-B kinase (IKK) (Tak and Firestein, 2001). NF-kB activates by numerous mediators such as ROS, TNF- $\alpha$, IL-1 $\beta$, and LPS (Gilmore, 2006). 
Stimulation of toll-like receptors (TLRs) also leads to activation of NF-kB and TLR4 is a receptor for LPS component of gram-negative bacteria (Tak and Firestein, 2001).

NF-kB expressed ubiquitously in the brain including in neurons, astrocytes, microglia, and oligodendrocytes (Srinivasan and Lahiri, 2015). It has been associated with the growth and development of dendrites, neuron survival, the formation of synaptic plasticity and long-term memory (Kaltschimidt et al., 2006). Surprisingly, in the brain, the activity of NF-kB is found to be lower in neuronal cells as compared to glial cells (Listwak et al., 2013). Evidence suggests that the NF-kB activation in the CNS may trigger gene transactivation and multicellular response associated with the initiation and progression of neurodegenerative diseases (Srinivasan and Lahiri, 2015). This may suggest that NF-kB signaling pathway could be a potential therapeutic target in neurodegenerative diseases. Since microglia are the primary phagocytic cells in the brain and play a critical role in neuroinflammation associated with neurodegenerative diseases, it would be very interesting to know how a change in microglia phenotype or cytoskeleton by inhibiting WAVE2 protein, effect NF-kB signaling in BV-2 microglial cells. 


\section{$\underline{\text { Research Purpose and Hypothesis: }}$}

The purpose of this study is to investigate the effects of WAVE2 protein in lipopolysaccharide (LPS) stimulated BV-2 microglial cells. We have hypothesized that WAVE2 will be a critical factor in microglia reactivity such that WAVE2 knock-down viruses will blunt microglial phenotype, which could be evident in the form of morphological changes, and changes in the expression of inflammatory regulators.

\section{Methods and Materials:}

\section{BV-2 cell line:}

Microglia have been studied extensively in animal models and in primary culture. At least 15-30 brains are required for preparing rodent microglia cells for any experiment (Henn et al., 2009). This results in the consumption of a large number of animals in biomedical research. In order to reduce animal consumption and save time, a cell line is an excellent alternative for the research purpose. BV-2 cells were first used for biomedical research in 1990 by Blasi and his team. These cells were derived from murine microglial cells that become immortalized after infected with v-raf/v-myc recombinant retrovirus and exhibit functional and phenotypical characteristics of reactive microglial cells (Blasi et al., 1990). Similar to primary microglia, BV-2 cells also express enzyme NADPH oxidase, which is involved in microglial-triggers neuronal damage in many neurodegenerative diseases (Wu et al., 2006). In 2009, Henn and her team have compared the gene expressions in both BV-2 cell and primary microglia after LPS stimulation. Similar to primary microglia, BV-2 cells have shown a parallel response, with overall $90 \%$ of the genes that 
induced by LPS in BV-2 cells, also found in primary microglia (Henn et al., 2009). BV-2 cell line is inexpensive and easy to maintain as compared to primary microglial cells.

\section{Study Design:}

Two experiments have been designed for the purpose of this study. Cells were plated in 96-wells plate for the experiment. In the first experiment, BV-2 cells were stimulated with lipopolysaccharide, LPS (1ug/ml) in complete media for 24 hours. Cells were then treated with CellRox green reagent for 30 minutes to study the oxidative stress. Images were taken using the EVOS Fluorescence imaging system from the Life Technologies. The same experiment was repeated using WAVE2 Si RNA (short interfering RNA) Adenovirus to block the expression of WAVE2 gene and protein on BV-2 cells. A flow chart of the two experiments and their timeline has been illustrated on the next page.

\section{What outcome would be assessed?}

In our study, we are going to assess and analyze three different outcomes in both control BV-2 cells and cells in which WAVE2 expression is inhibited by WAVE2 (siRNA).

- Western blotting to confirm WAVE2 inhibition

- Oxidative stress: using CellRox green reagent

- Morphology of BV-2 cells (analyzing shape and size of cells in each group)

- Immunofluorescence staining for nuclear factor kappa-B (NF-kB) 


\section{Experiment 1:}

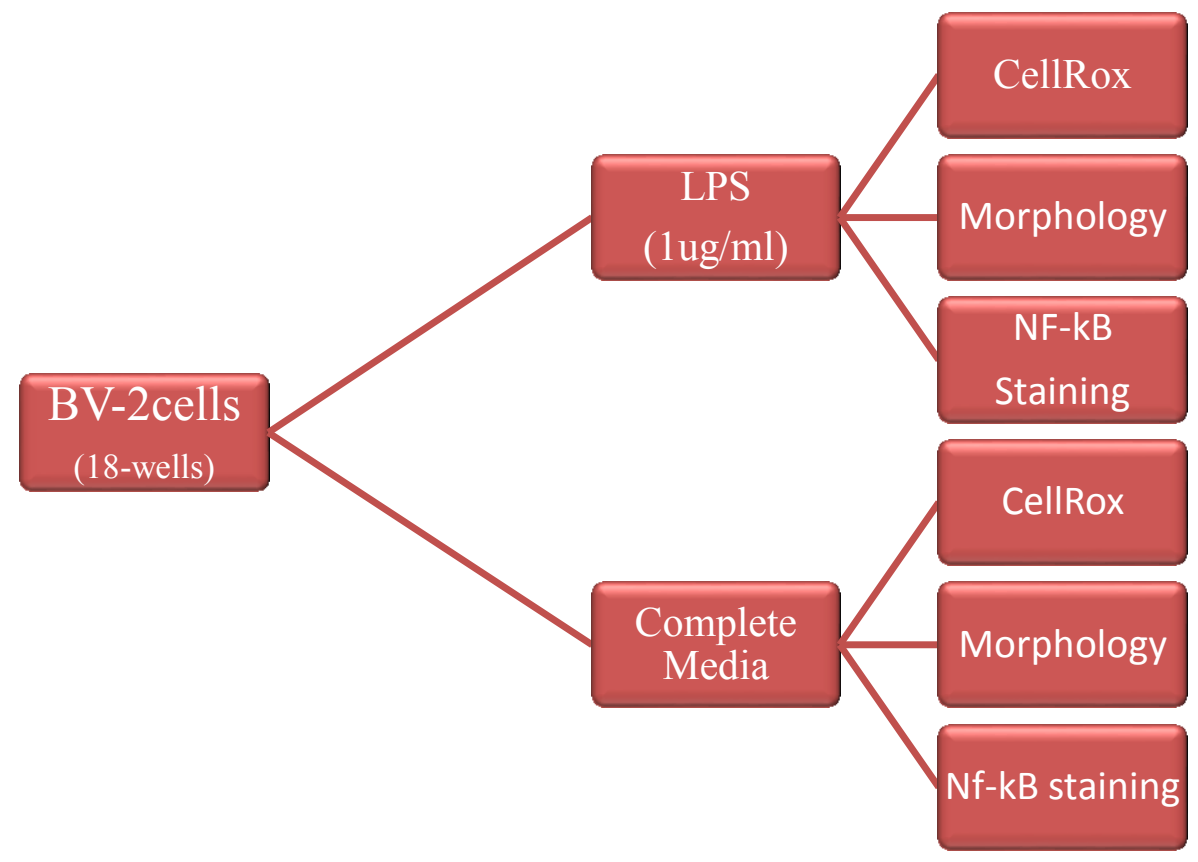

Timeline for Experiment 1:

Cells were plated in 96-

well plate $\left(1 \times 10^{4} \mathrm{cell} / \mathrm{ml}\right)$
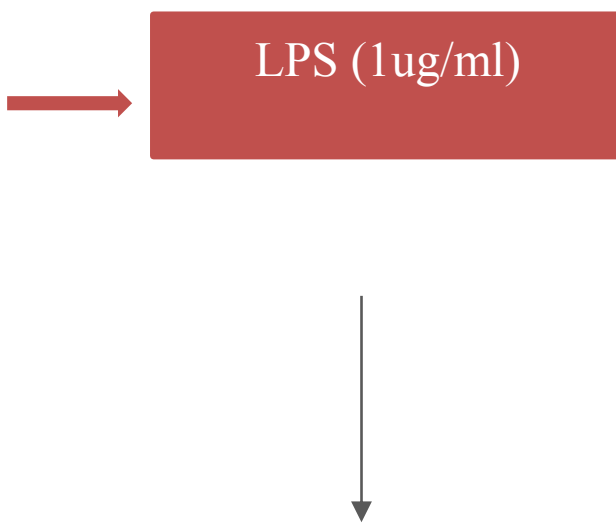

1-2 days to reach $20-30 \%$ confluency
Treatment with CellRox reagent

And PFA fixation

$\mathrm{BV}-2$ cells were incubated at $37^{\circ} \mathrm{Cin} 5 \% \mathrm{CO}_{2}$ and $95 \% \mathrm{O}_{2}$

Figure 4: Study design and timeline for the experiment 1 


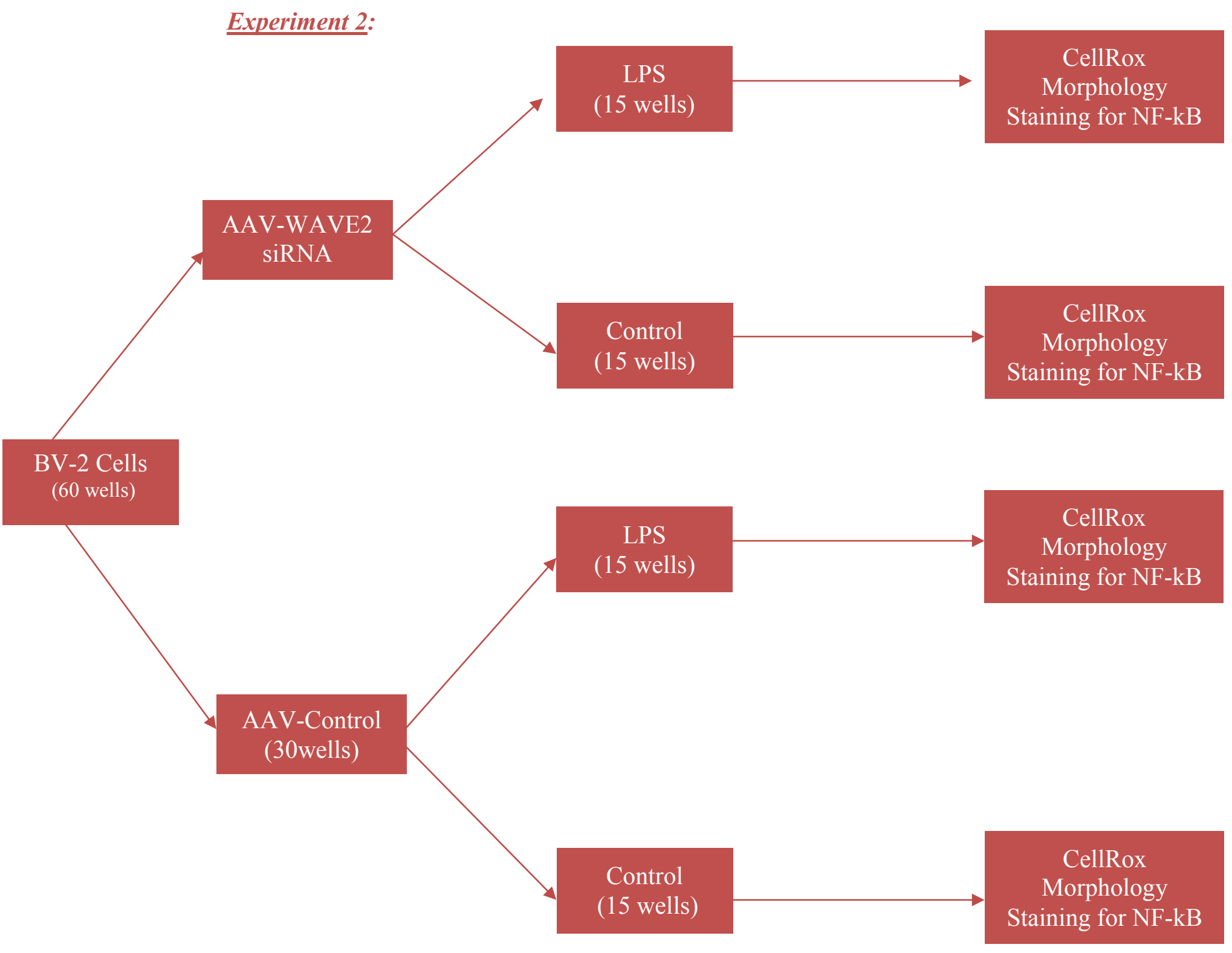

Figure 5A: Study design for the Experiment 2 


\section{Timeline for the second experiment:}

Cells were plated in

96-well plate

$\left(1 \times 10^{4}\right.$ cells $\left./ \mathrm{ml}\right)$
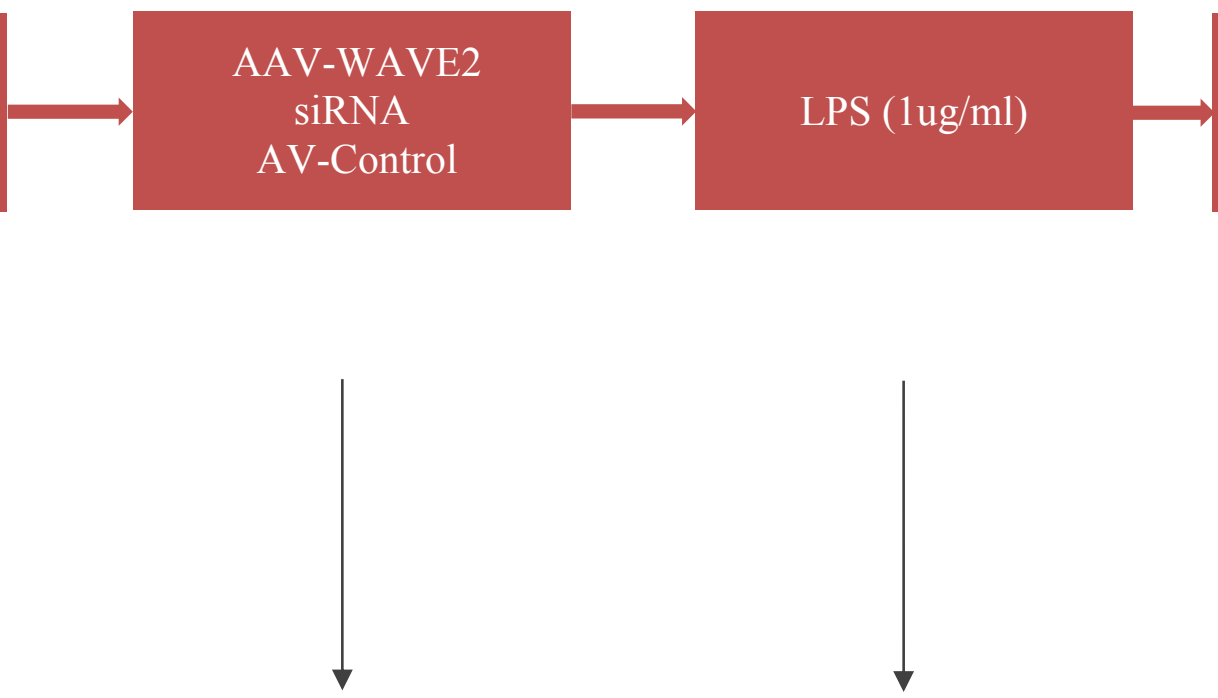

For 24 Hours

For 24 Hours

1-2 days to reach 20 -

$30 \%$ confluency
Treatment with

CellRox reagent.

PFA Fixation

$\mathrm{BV}-2$ cells were incubated at $37^{\circ} \mathrm{Cin} 5 \% \mathrm{CO}_{2}$ and $95 \% \mathrm{O}_{2}$

Figure 5B: Timeline for the second Experiment 


\section{Reagents:}

Tissue culture materials were purchased from Sigma Life Science. Dulbecco's Modified Eagle Media (DMEM) was obtained from Sigma-Aldrich (St. Louis, MO, USA). Fetal Bovine Serum (FBS), antibiotics PennStrep (penicillin-streptomycin) were purchased from Gibco. Lipopolysaccharide (LPS) was obtained from Sigma and was reconstituted at $1 \mathrm{mg} / \mathrm{ml}$ aliquot in complete media. Complete media $(\mathrm{CM})$ was made in the tissue culture lab using $89 \%$ of DMEM with high glucose, $1 \%$ of PennStrep antibiotics and $10 \%$ of FBS. Sterile Phosphate Buffer Solution (PBS) was purchased from Sigma Life Science. CellRox Green Reagent was purchased from Invitrogen by Thermo Fisher. DAPI, NucBlue live cells stain ready probes reagent, was also purchased from Invitrogen. PNF-kB P65 fluorescent primary antibody and mouse-488 secondary antibody obtained from SantaCruz. WAVE2 siRNA Adenovirus was a kind gift from Park lab from the University of Ottawa.

\section{Cell Culture:}

BV-2 murine cell line was a kind gift from the David Park lab, University of Ottawa. Cells were maintained in high glucose Dulbecco's modified Eagle's medium (DMEM) supplemented with 10\% fetal bovine serum, 100 units/ml penicillin, and 100 $\mathrm{mg} / \mathrm{ml}$ streptomycin. BV-2 cells were grown in T-75 flask, with the concentration of $1 \times 10^{5}$ cells $/ \mathrm{ml}$ in $10 \mathrm{ml}$ of complete media (CM). Complete media was changed twice a week since the cells grow confluent very quickly and cells were observed every 2-3 days. BV-2 cells were passaged once a week. All cells were incubated at $37{ }^{\circ} \mathrm{C}$, in $5 \% \mathrm{CO}_{2}$ and $95 \%$ relative humidity. 


\section{Cell Passaging:}

BV-2 cells maintained in T-75 flask were passaged every week. For this purpose, all but 2-3 $\mathrm{ml}$ of complete media from the flask were removed using a $10 \mathrm{ml}$ pipettor. Cells were dislodged from the surface of the flask using a sterile cell scraper and the resulting cell suspension were placed in a $15 \mathrm{ml}$ conical tube. These cells were then centrifuged at 1200 RPM for 5 minutes. Supernatant was aspirated without disturbing the pellets. $1 \mathrm{ml}$ of fresh media was added to the pellets and triturated vigorously to break the cell suspension. Cells were then counted using a hemocytometer. Flask was re-seeded with the required concentration of $1 \times 10^{5}$ cell $/ \mathrm{ml}$ in $10 \mathrm{ml}$ of complete media.

\section{Plating Experiment:}

For all experiments, cells were plated in 96 well-plate, with the required concentration of $1 \times 10^{4}$ cells $/ \mathrm{ml}$ in complete media. $100 \mathrm{ul}$ of required volume is added to each well and the cells were allowed to grow until it reaches $20-30 \%$ confluency. Plated cells were incubated at $37^{\circ} \mathrm{C}$, in $5 \% \mathrm{CO}_{2}$ and $95 \% \mathrm{O}_{2}$ for $24 \mathrm{hrs}$ before treatment with LPS started. In total, 18-wells were plated with BV-2 cells for the first experiment and 60 wells for the second experiment. Treatment was applied on half of these wells and the other half used as control. When the BV2 cells achieved 20-30\% confluency, cells were treated with $1 \mathrm{ug} / \mathrm{ml}$ of LPS in complete media and incubated for 24 hours.

\section{Transfection of BV-2 cells with WAVE2 siRNA:}

We used the Adeno-associated virus (AAV) vector for the delivery of short interfering RNA (siRNA) to suppress the expression of WAVE2 gene in BV-2 cells. The virus concentration we have for our experiments are; WAVE2 under expressers, Ades Iba1 Zs-yellow shWAVE $7.9 \times 10^{10}$ and for the control virus, Ades Iba-1 Zs-yellow H1 $1.5 \mathrm{x}$ 
$10^{10}$. RNA-interference (RNAi) refers to a biological process in which the gene expression or translation is inhibited by RNA molecule. Two types of RNA-molecules are central to the process of RNA interference, microRNA (miRNA) and siRNA. These RNA molecules can degrade messenger RNA (mRNA) by directing the enzyme complexes and decrease their activity by preventing translation, via post-transcriptional gene silencing. AAVvector has been successfully used in our lab previously to silence the expression of different genes. Using AAV-vector for siRNA delivery has many advantages such as its ability to infect both dividing and nondividing cells and a wide range of host (Tomar, Matta \& Chaudhary, 2003). In addition, it is known that wild type AAV never cause any disease and also cannot replicate in the infected cells (Tomar et al., 2003).

For the second experiment, BV2 cells were plated in 96-well plate and 60 wells were used for the experiment. When the cells reached 20-30\% confluency, cells in half of these wells were treated with WAVE2 siRNA diluted in complete media. Cells in the remaining 30 wells were treated with AAV without the WAVE2 siRNA and used as control. BV2 cells were allowed to grow for 24 hours in an incubator with $5 \% \mathrm{CO}_{2}, 95 \%$ $\mathrm{O}_{2}$ at $37{ }^{\circ} \mathrm{C}$. After 24 hours, these cells were treated with LPS (1ug/ml) diluted in complete media for 24 hours.

\section{Western blot analysis:}

Western blot analysis was performed to evaluate the expression of WAVE2 protein in both WAVE2 siRNA treated BV-2 cells and in control. For this purpose, cells were grown in two T-25 flasks with a concentration of $1 \times 10^{5}$ cells $/ \mathrm{ml}$ in $3 \mathrm{ml}$ of complete media. After 2-3 days cells were transfected with WAVE2 siRNA using Adeno-associated viral vector. Cells in the other flask were treated with control virus. After 24 hours of 
transfection, proteins were extracted and western bloat analysis was performed for WAVE2 protein.

\section{Measurement of Oxidative stress using CellRox:}

CellRox green reagent was used to measure oxidative stress in both LPS stimulated and unstimulated BV2 cells. When in a reduced state, this cell-permeant dye is weakly fluorescent. Upon oxidation with reactive oxygen species (ROS), it exhibits the bright green photostable fluorescence. Oxidative stress results from an imbalance between the production of ROS and the cell's ability to scavenge them. Several studies have now confirmed that ROS play a very important role in inflammation and the progression of several diseases such as atherosclerosis (Bonomini et al., 2008), aging and age-related degenerative disorders (Uttara et al., 2009). CellRox solution diluted in CM using 1ul of CellRox green reagent in 500ul of CM. One drop of DAPI NucBlue live cell stain also added to this solution. 50ul of CellRox solution was put in 6 wells, 3 wells with LPSstimulated BV2 cells and the other 3 wells as control and incubated for 30 minutes. For each culture condition, fluorescent images of 5 different random fields were acquired using a $20 \mathrm{X}$ fluorescence objective. The quantitative analysis representing the corrected cell fluorescence intensity to ROS was calculated using the Image J (1.46r) software as follows: [(Integrated Density/ Area) - Adjusted Background].

\section{Immunofluorescence staining for NF-kB:}

After treatment with LPS for 24 hours, plated BV-2 cells were fixed with 4\% Paraformaldehyde (PFA) in PBS, 100ul in each well and incubated for 15 minutes. Cells were then washed with sterile PBS (100ul in each well), three times for 5 minutes each. BV-2 cells were blocked for 30 minutes using blocker solution made up of $2 \%$ BSA and 
$0.1 \%$ of Triton-X in PBS. BV-2 cells were incubated in the primary solution for one hour. The primary solution was made by mixing $0.1 \%$ of BSA in PBS and pNF-kB p65 primary antibody in a ratio of 1:250. After one hour incubation, cells were washed three times in PBS for 5 minutes each. We use mouse secondary fluorescence antibody M-488 in a ratio of 1:1000 and the cells were incubated for 30 minutes in secondary solution. Three PBS wash was done for 5 minutes and images were taken using the EVOS Fluorescence Color imaging system. For each culture condition, fluorescent images of 5 random fields were acquired using a 20X fluorescence objectives. The quantity analysis representing the corrected cell fluorescence intensity was calculated using the Image J (1.46r) software as follows: [(Integrated Density/ Area) - Adjusted Background].

\section{Morphology:}

$\mathrm{BV}-2$ cells were incubated in 96-well plate in complete media in $5 \% \mathrm{CO} 2$ and 95 $\%$ air at $37 \mathrm{oC}$ for $24 \mathrm{hrs}$. Cells were stimulated with LPS (1ug/ml) and incubated for 24 hrs. BV2 cells were fixed with $4 \%$ paraformaldehyde for 30 minutes at room temperature and washed three times with sterile PBS for 5 minutes each. Images were taken using the EVOS Fluorescence imaging system for morphology. We compare morphology by analyzing the length and width of the BV-2 cells using the image-J software.

\section{Image Analysis:}

All images were analyzed using Image-J (version 1.46r). Image-J is a public domain Java-based image processing and analysis program inspired by National Institutes of Health (NIH) Image for the Macintosh. It can display, edit, analyze, process and save images. It can calculate area and pixel value statistics and also measure distances and angles. 


\section{Statistical Analysis:}

All data were analyzed by ANOVA. We run independent sample T-test to analyze the data for the experiment one and two-way ANOVA for the second experiment. Data were evaluated using a StatView (version 5.0) statistical software package from SAS

Institute Inc. All data were represented as mean \pm standards error of mean (SEM). P-value $<0.05$ will be considered significant. 


\section{$\underline{\text { Results: }}$}

\section{LPS effects on morphological changes of BV-2 microglial cells:}

We first observed the morphology of BV-2 microglial cells after LPS stimulation. BV-2 cells were treated with LPS $(1 \mathrm{ug} / \mathrm{ml})$ in complete media and incubated for 24 hours. Images were taken after fixing the cells with $4 \%$ paraformaldehyde. As seen in the picture, LPS stimulation significantly alter the morphology of BV-2 microglial cells $(F=4.793$, * $\mathrm{p}=0.001)$. The morphology of control BV-2 cells showed small cell body and distal processes, characteristics of "ramified" or "resting" microglia. LPS-stimulated BV-2 appears round with very short or no processes.

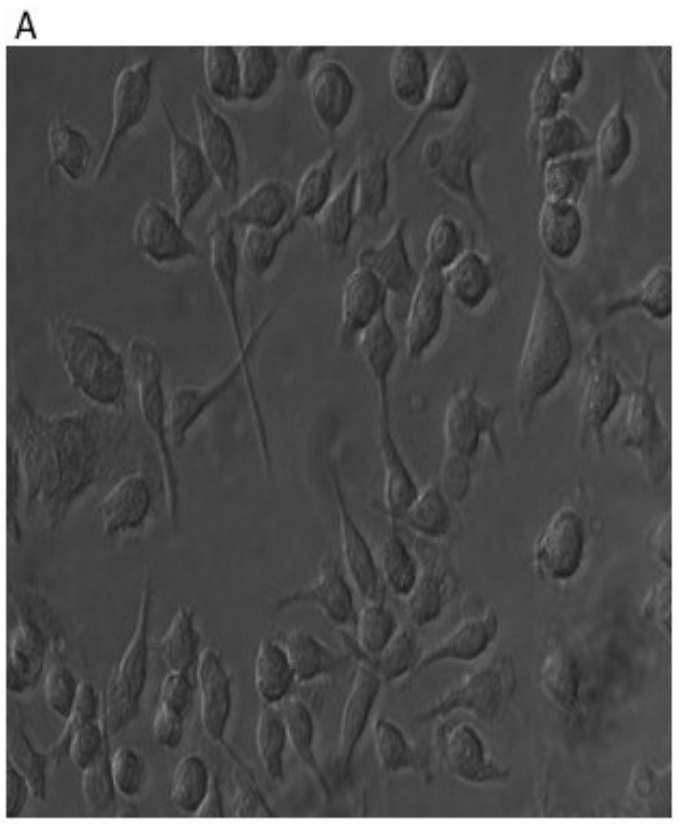

Saline

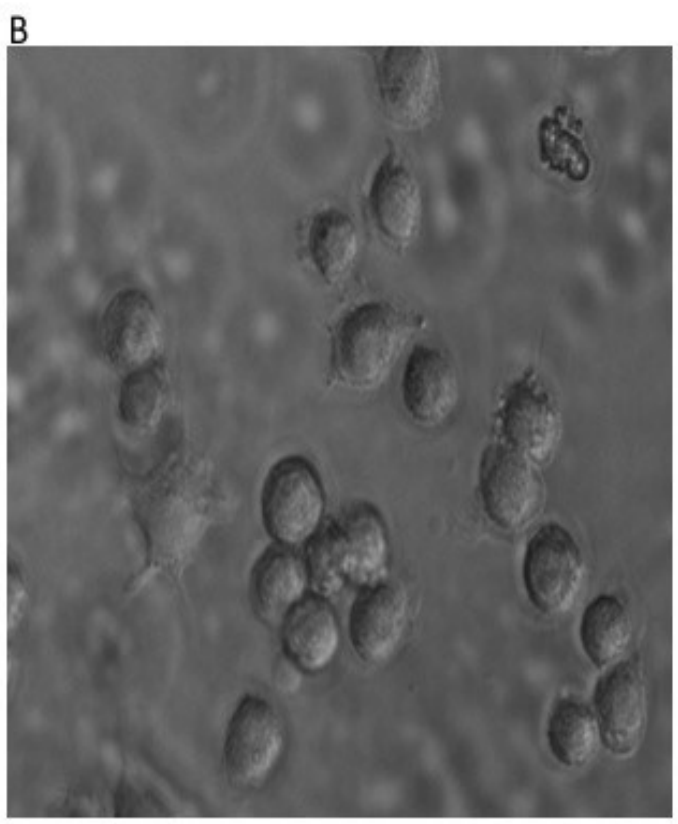

LPS

Figure 6 (A\& B): LPS effect on morphology of BV-2 microglial cells. Stimulated cells appear round with no cellular projections or processes, feature of activated microglia, after 24 hours exposure to LPS (B). Unstimulated BV-2 cells show typical characteristics of resting or ramified microglial cell, with long projections and processes (A). Image were analyzed comparing length and width of each cells using image-J software. 
$\mathrm{C}$

\section{BV-2 cells Morphology}

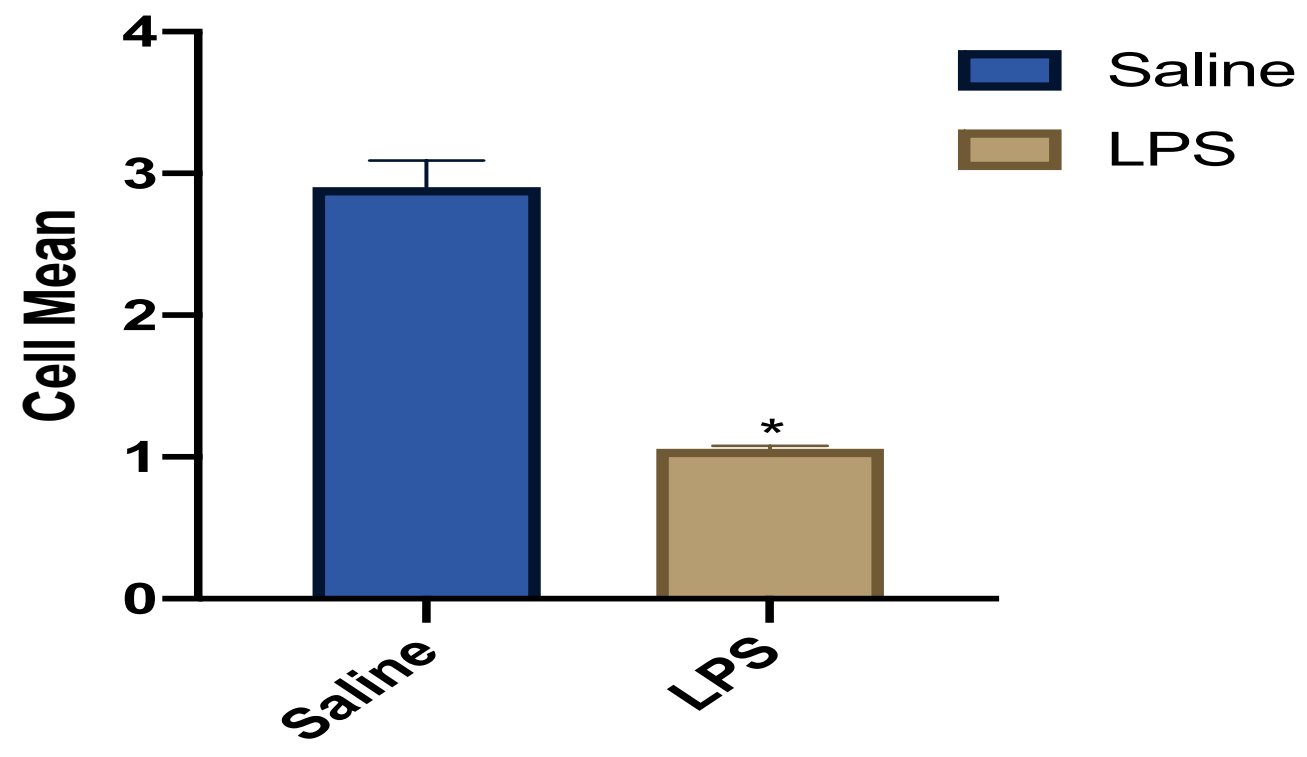

Treatment

Figure 6C: The effect of LPS on BV-2 microglial cells morphology. BV-2 microglial cells were stimulated for 24 hours with $1 \mathrm{ug} / \mathrm{ml}$ of LPS. Cells appearance was analyzed comparing length and width of BV-2 cells using Image-J software. LPS stimulation significantly alter the morphology of $\mathrm{BV}-2$ microglial cells $(\mathrm{F}=4.793, * p$-value $=0.001)$, as compared with control group. LPS stimulated BV-2 cells appears rounder with very few or no cellular process. 


\section{Effect of LPS on oxidative stress in BV-2 microglia:}

Intracellular oxidative stress was evaluated using fluorescence microscopy in LPS-stimulated BV-2 cells and in control, using membrane permeable CellRox green reagent, a fluorescence probe that produces bright green fluorescence upon oxidation. LPS significantly upregulates the oxidative stress in BV-2 microglial cells $(\mathrm{F}=1.554$, ${ }^{*} \mathrm{p}=0.000$ ), as indicated by increased uptake of CellRox green reagent by LPS stimulated BV-2 cells as compared to control. Fig. 7.

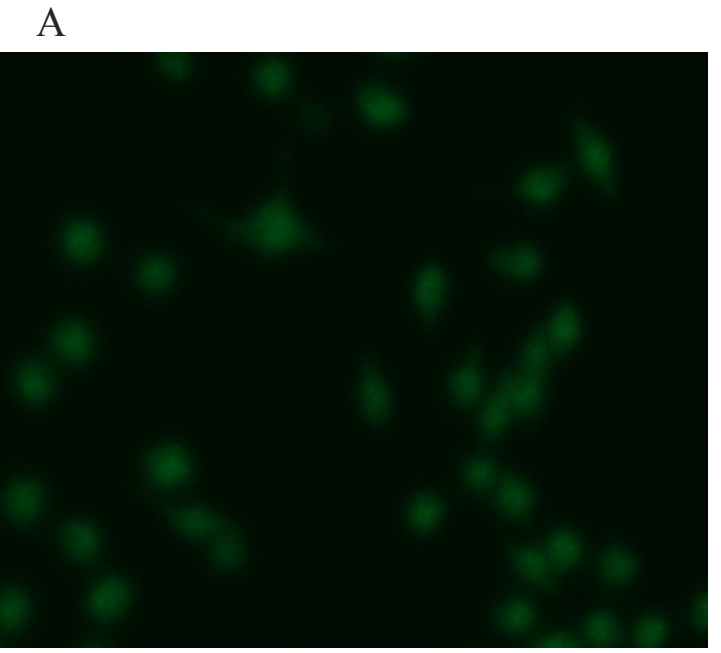

Saline

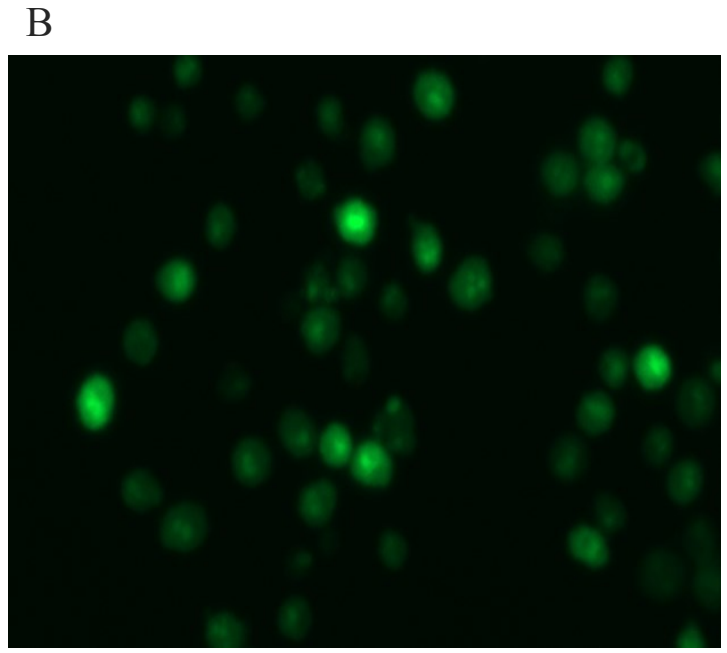

LPS

Figure 7 (A\& B): LPS effect on oxidative stress in BV-2 microglial cells: BV-2 microglial cells were treated with LPS $(1 \mathrm{ug} / \mathrm{ml})$ for 24 hours. Cells were then treated with CellRox green reagent for half an hour. LPS stimulated BV-2 microglial cells exhibit bright green fluorescence (B), as compared to control (A). The quantity analysis representing the corrected cell fluorescence intensity was calculated using the Image J (1.46r) software as follows: [(Integrated Density/ Area) - Adjusted Background]. 
$\mathrm{C}$

\section{Oxidative stress in BV-2 cell}

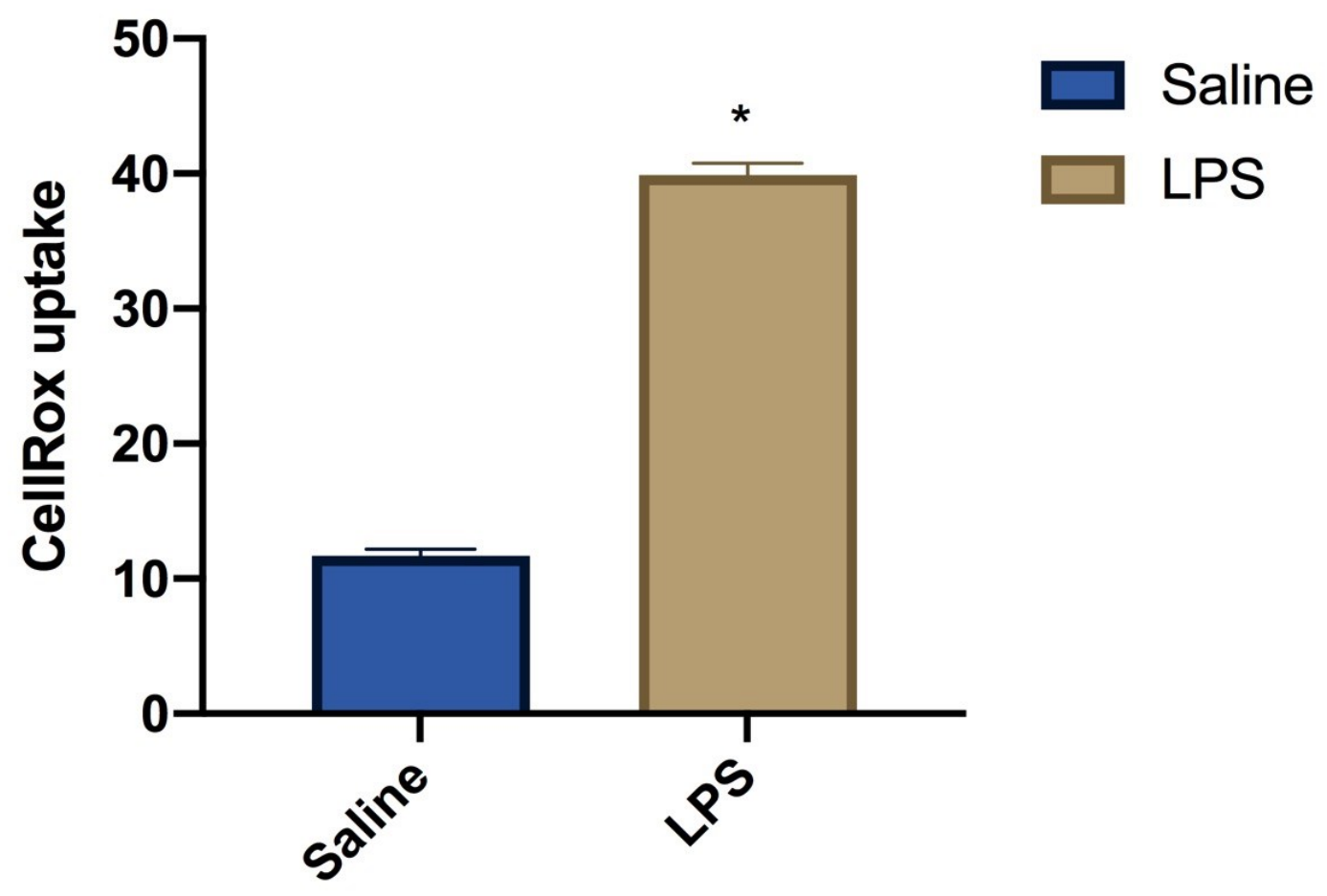

Treatment

Figure 7C: The effect of LPS on oxidative stress in BV-2 microglial cells. Oxidative stress in BV-2 microglial cells were tested using CellRox green reagent for 30 minutes. LPS significantly upregulates oxidative stress in BV-2 microglial cells $(\mathrm{F}=1.554, \mathrm{p}<0.05)$. 


\section{Effect of LPS on NF-kB signaling:}

For this purpose, immunofluorescence staining for NF-kB was performed using pNF-kB p65 rat primary antibody in a dilution of 1:250. We use mouse M-488 secondary antibody in a dilution of 1:1000. Images were taken under green channel using EVOS fluorescence image system. LPS stimulated BV-2 microglia exhibit bright green fluorescence. LPS significantly upregulates NF-kB signaling in BV-2 microglia cells as compared to control $\left(\mathrm{F}=0.676,{ }^{*} \mathrm{p}=0.00\right)$.

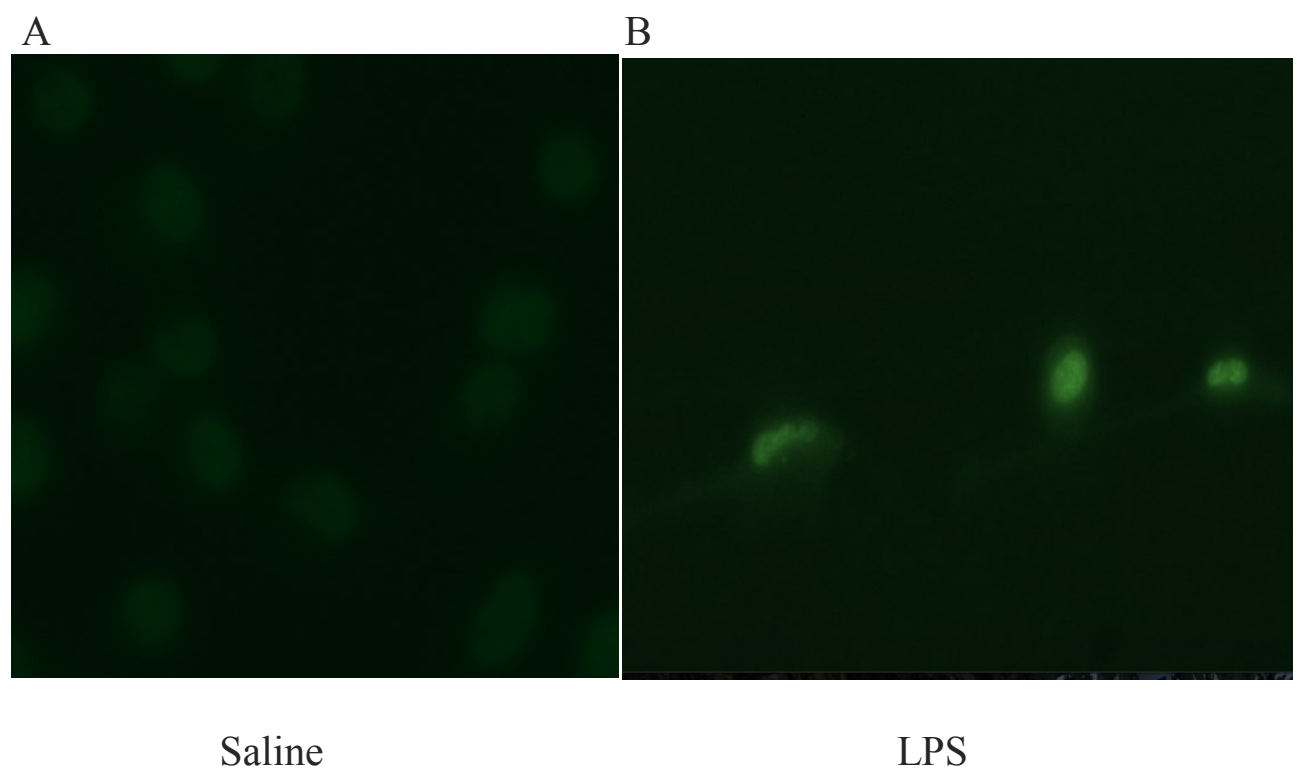

Figure 8 (A\&B): Immunofluorescence staining for NF-kB Expression in Bv-2 microglial cells. BV-2 cells were treated with LPS $(1 \mathrm{ug} / \mathrm{ml})$ for 24 hours and fixed with $4 \%$ paraformaldehyde for 15 - 30 minutes before immunofluorescence staining for NF-kB. LPS-stimulated cells exhibit bright green fluorescence (B) as compared to control cells (A). 


\section{Immunofluorescence}

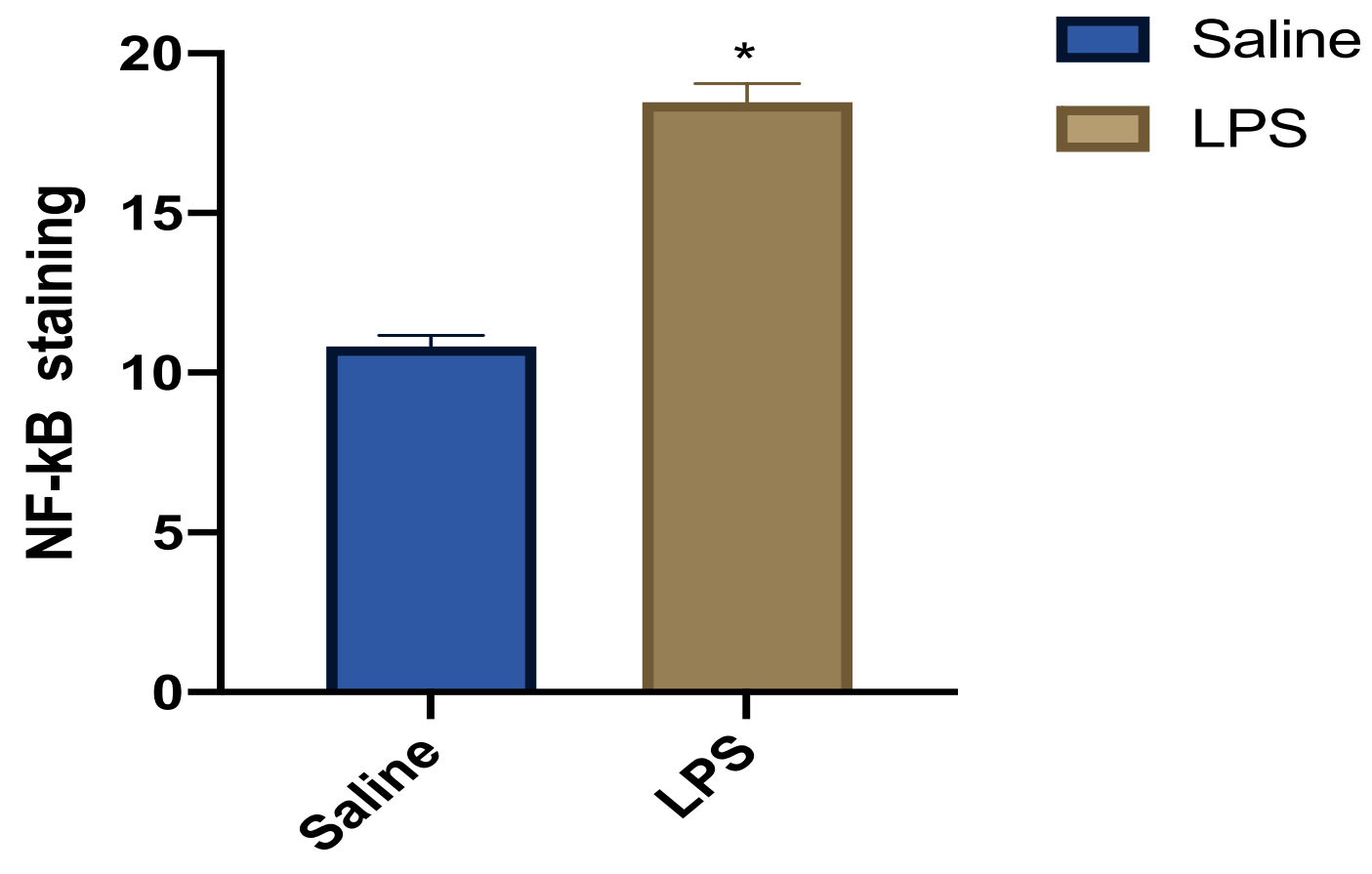

Treatment

Figure 8C: LPS effect on NF-kB signaling in BV-2 cells: LPS significantly upregulates NF-kB signaling in BV-2 microglial cells $(\mathrm{F}=0.676, * \mathrm{p}=<0.05)$. The quantity analysis representing the corrected cell fluorescence intensity was calculated using the Image J (1.46r) software as follows: [(Integrated Density/ Area) - Adjusted Background]. 


\section{Decrease WAVE2 expression after transfection with AAV-WAVE2 siRNA:}

Western blot analysis was performed after BV-2 cells were transfected with adenoassociated virus vector WAVE2 siRNA. Transfected cells were incubated for 24 hours before the sample protein was collected by centrifuging. WAVE2 siRNA were not able to completely ablate WAVE2 expression, which could indicate the duration of transfection and number of virus particles require to infect each cell might be a factor.

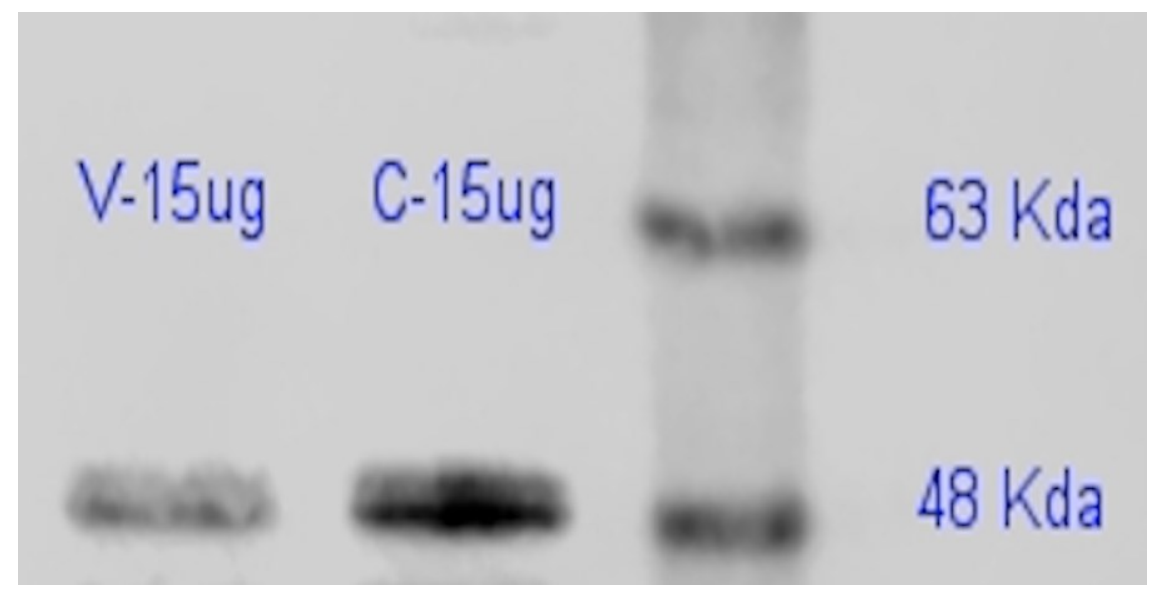

WAVE2 Expression in BV-2 microglial cells

Figure 9: WAVE2 siRNA decrease expression of WAVE2 protein in BV-2 cells: Transfection of BV-2 microglial cells with WAVE2 siRNA AAV results in reduce expression of WAVE2 protein as compared to control. Sample was collected after transfecting BV-2 cells in two different T-25 flasks. "V" indicates sample was collected from (AAV)WAVE2 siRNA transfected cells and "C" from the control virus. 15ug of sample protein was collected for western blot. Result shows an obvious decrease in the expression of WAVE2 protein after transfected with virus for 24 hours. 
LPS significantly upregulates oxidative stress in BV-2 microglial cells and this effect is independent of WAVE2 inhibition:

We first determined if WAVE2 knock down could change inflammatory effects of LPS in BV-2 microglial cells in the form of oxidative stress. There was no significant interaction observed between two different treatment groups $(\mathrm{F}=0.005, \mathrm{p}=0.946)$. We have found that LPS significantly upregulates oxidative stress in BV-2 cells $(\mathrm{F}=14.456$, $\left.{ }^{*} \mathrm{p}=0.002\right)$, but WAVE2 knock down does not have any significant effect on oxidative stress in BV-2 microglial cells $(\mathrm{F}=0.209, \mathrm{p}=0.653)$.

A

\section{Interaction Bar Plot for CellRox Effect: Virus * Treatment}

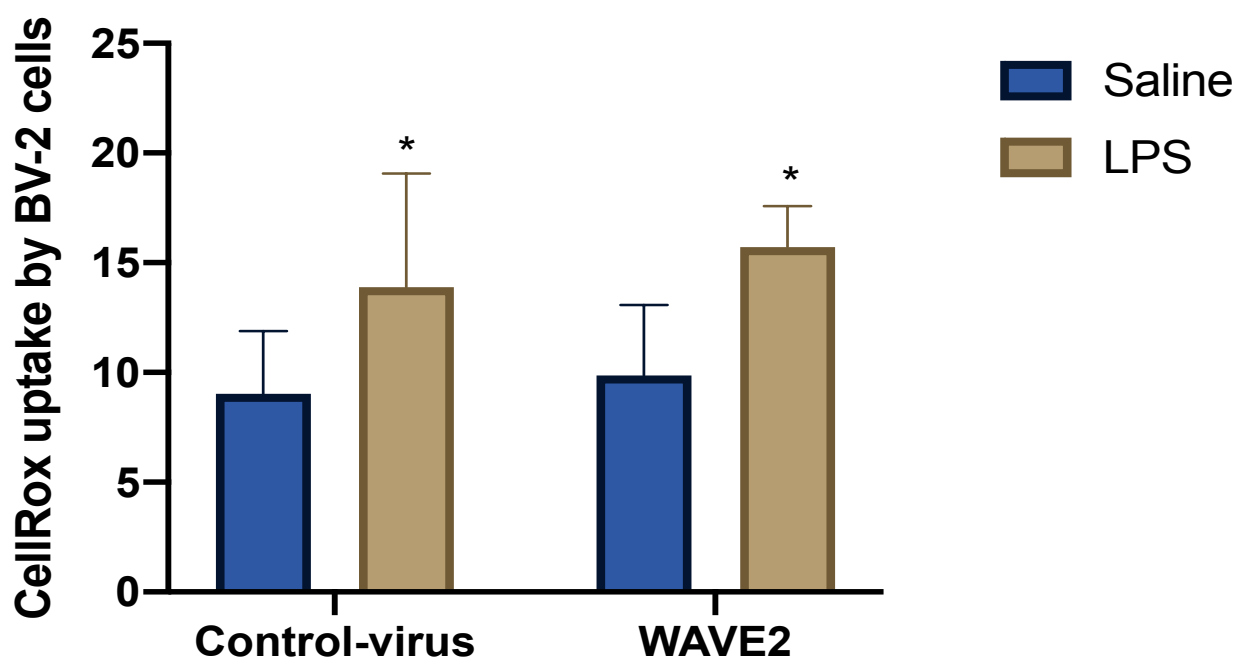

Figure 10A: Effect of WAVE2 inhibition on oxidative stress in LPS-stimulated and un-stimulated BV-2 microglial cells. LPS stimulated BV-2 microglial cells show significant upregulation in oxidative stress when tested with CellRox green reagent $\left(\mathrm{F}=14.456,{ }^{*} \mathrm{p}=0.002\right)$. WAVE2 knock-down cells do not have any significant effect on oxidative stress $(\mathrm{F}=0.209, \mathrm{p}=0.653)$. 


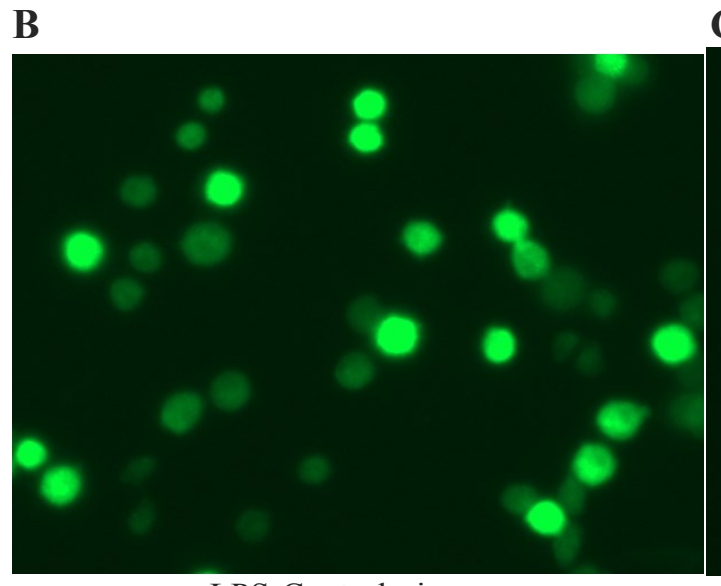

LPS-Control-virus
C

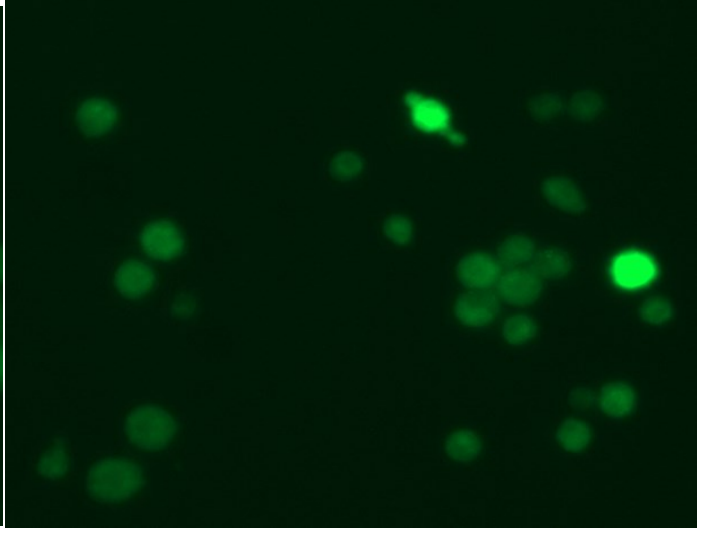

LPS-Wave2

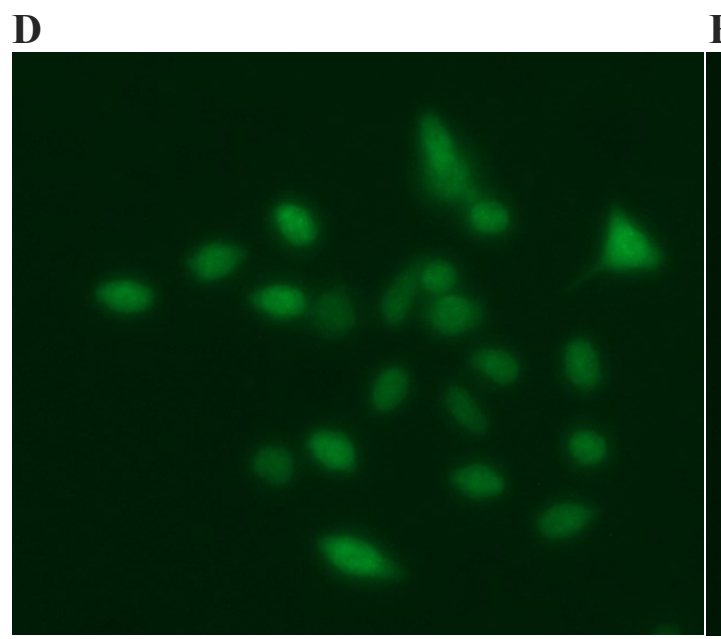

Saline-Control-virus
$\mathbf{E}$

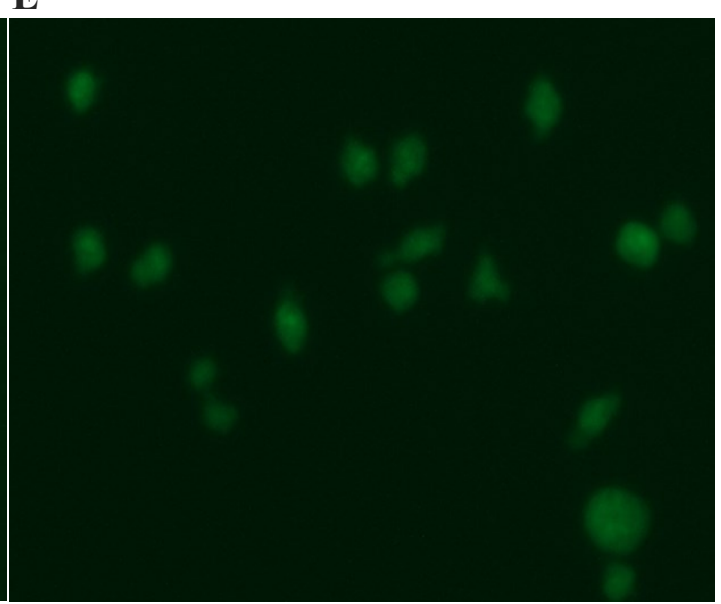

Saline-Wave2

Figure 10: Evaluation of oxidative stress in BV-2 microglia using CellRox green reagent. BV-2 cells were plated in 96-well plate and incubated until it reaches $20-30 \%$ confluency. Cell were then transfected with either Adeno-associated virus WAVE2 siRNA $(\mathrm{C} \& \mathrm{E})$ or with control-virus (B \& D) for 24 hours. Half of the wells in each group were treated with LPS for 25 hours and other half as control. Intracellular oxidative stress in each group was evaluated using CellRox green reagent. LPS significantly upregulates oxidative stress in BV-2 microglia. The quantity analysis representing the corrected cell fluorescence intensity was calculated using the Image J (1.46r) software as follows: [(Integrated Density/ Area) - Adjusted Background]. 
WAVE2 knock-down virus does not change inflammatory phenotype of BV-2

microglia:

We analyze the morphology of LPS stimulated and unstimulated BV-2 microglial in both WAVE2 knock-down cells and in control. No significant interaction between WAVE2 knock-down and control virus BV-2 cells $(\mathrm{F}=1.878, \mathrm{p}=0.190)$. The only significant effect that was noticed, is the treatment effect. LPS significantly change the morphology of BV-2 microglial cells $\left(\mathrm{F}=101.827,{ }^{*} \mathrm{p}=0.00\right)$. LPS stimulated cells appears round and have few or no cellular processes, as compare to control cells. There is no significant virus effect noticed in BV-2 microglial cells $(\mathrm{F}=0.014, \mathrm{p}=0.908)$.

A

Interaction Bar Plot for Morphology
Effect: Virus * Treatment

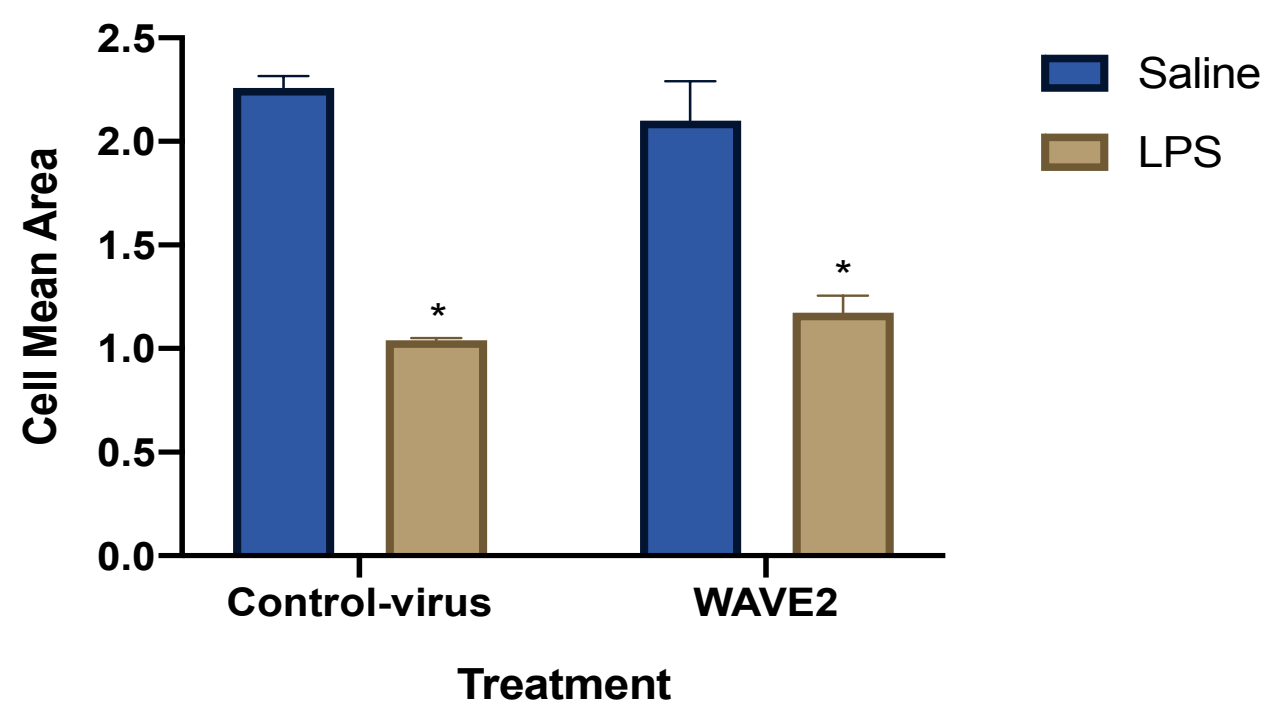

Fig. 11A: Effect of WAVE2 inhibition on inflammatory phenotype of LPS-stimulated and unstimulated BV-2 microglial cells. We compare the size and shape of LPSstimulated and unstimulated BV-2 cells in both WAVE2 knock-down and in control cells. LPS significantly affects the appearance of BV-2 microglial cells $\left(\mathrm{F}=101.827,{ }^{*} \mathrm{p}=0.00\right)$, but this effect is not altered by WAVE2 inhibition. The quantity analysis representing the corrected cell fluorescence intensity was calculated using the Image J (1.46r) software as follows: [(Integrated Density/ Area) - Adjusted Background]. 


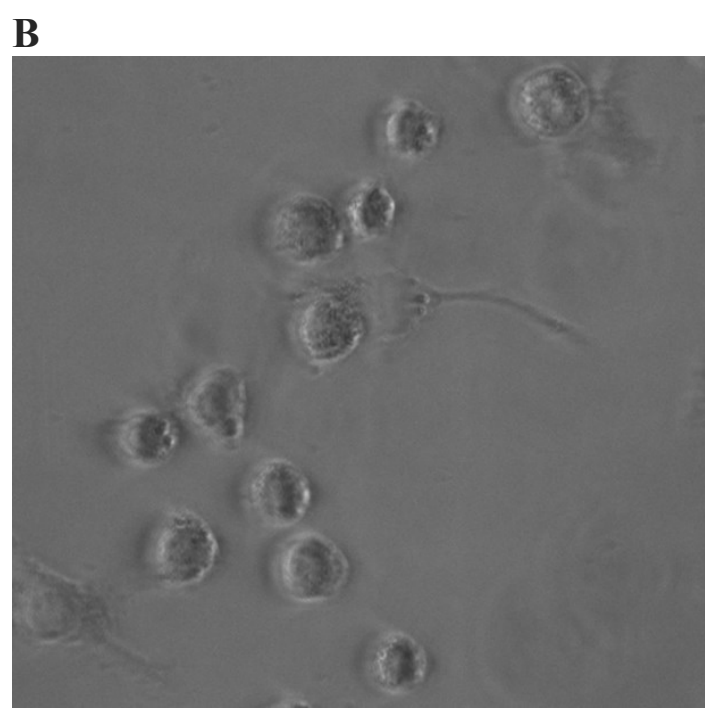

LPS-Control virus

$\mathbf{D}$

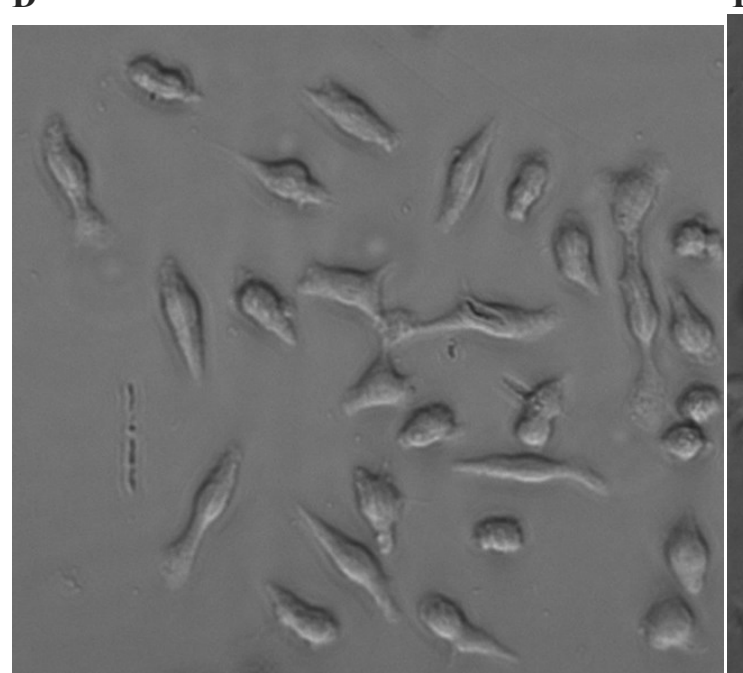

Saline-Control virus
C

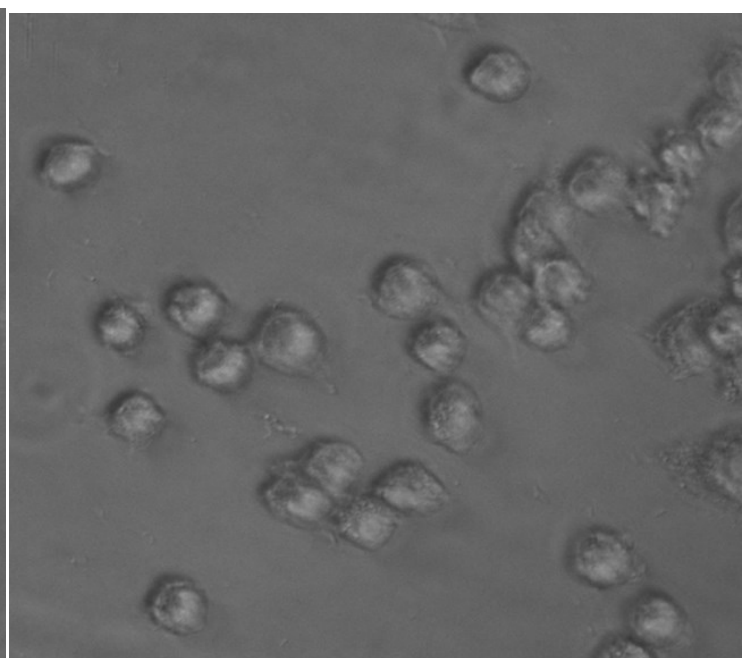

LPS-Wave2

$\mathbf{E}$

Figure 11: Effect of WAVE2 on stimulated and un-stimulated BV-2 microglial cells appearance. Images were taken after cell-fixation with $4 \%$ Paraformaldehyde. We used $20 X$ magnification to capture the images. Images were analyzed using Image-J software, comparing length and width of cells in 5 different microscopic field. There is only significant treatment effect (LPS) noticed (A) $\left({ }^{*} p=0.00\right)$. There is no significant effect on BV-2 microglia cells morphology noticed by WAVE2 inhibition (B\&D) $(\mathrm{F}=0.014$, $\mathrm{p}=0.908)$. 


\section{WAVE2 inhibition does not affect NF-kB Signaling:}

Immunofluorescence staining for NF-kB was performed for all four groups to analyze the change in the inflammatory status of WAVE2 knock-down and in control BV2 microglial cells. No interaction was observed between WAVE2 siRNA and control virus group $(F=0.295, p=0.594)$. No significant effect of LPS stimulation was observed on NF$\mathrm{kB}$ signaling $(\mathrm{F}=0.424, \mathrm{p}=0.524)$. WAVE2 inhibition also does not cause any significant change in inflammatory signaling of $\mathrm{NF}-\mathrm{kB}$ pathway $(\mathrm{F}=0.405, \mathrm{p}=0.533)$. (Fig. 12).

A

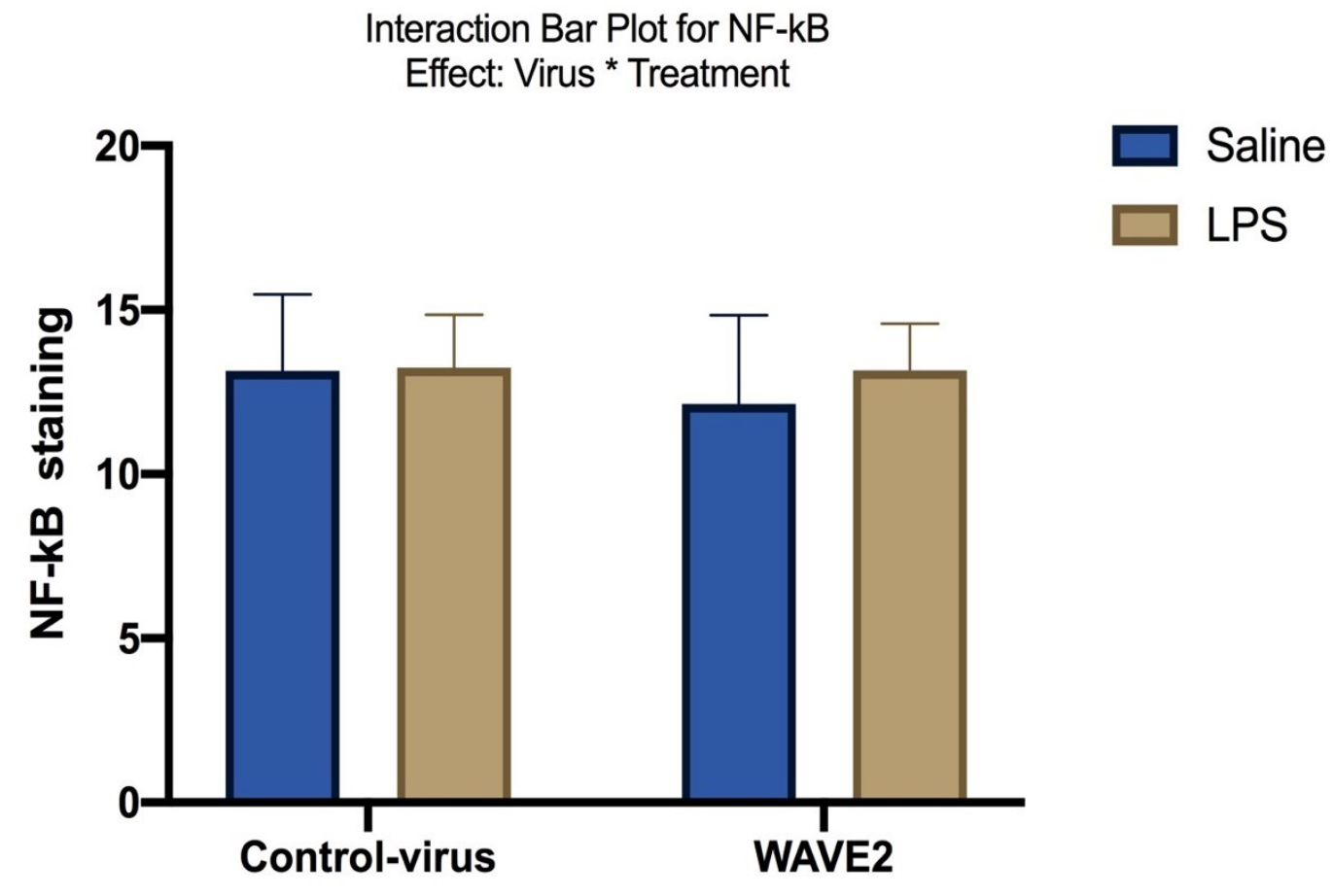

Treatment

Figure 12A: Effect of WAVE-2 knock-down on NF-kB signaling. No significant treatment or virus effect were noticed on immunofluorescence staining pattern for NF-kB signaling in LPS treated and untreated BV-2 microglial cells. 
B

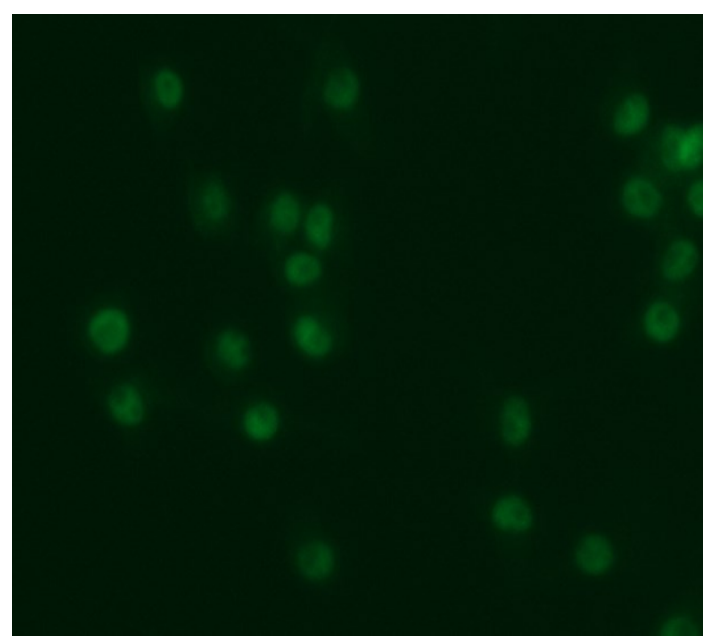

LPS Control-virus

$\mathrm{D}$

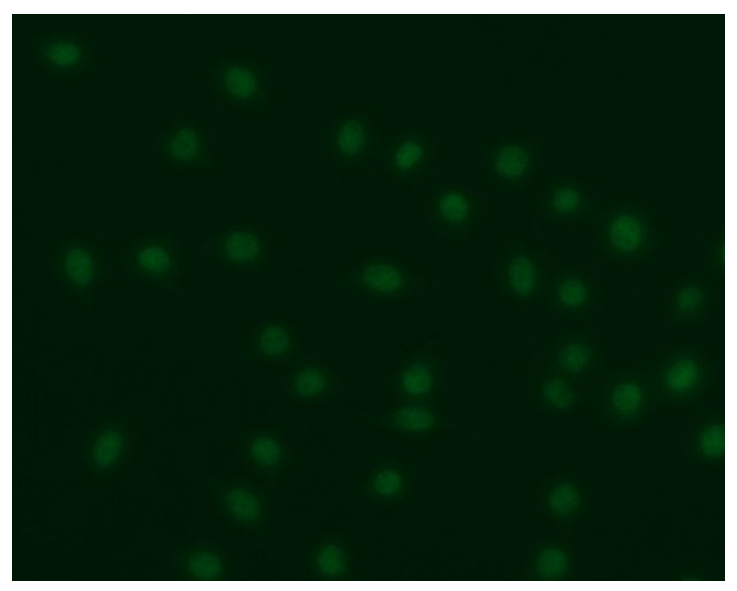

Saline-control-virus
$\mathrm{C}$

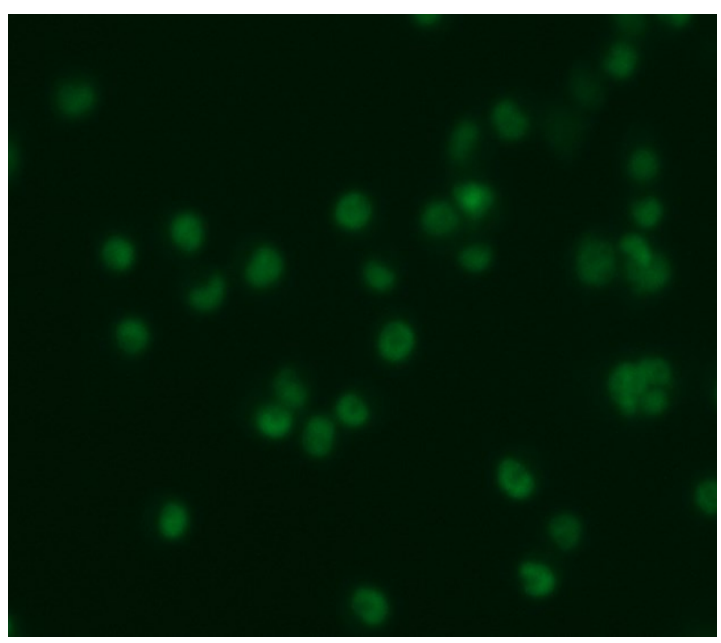

LPS-Wave2

$\mathrm{E}$

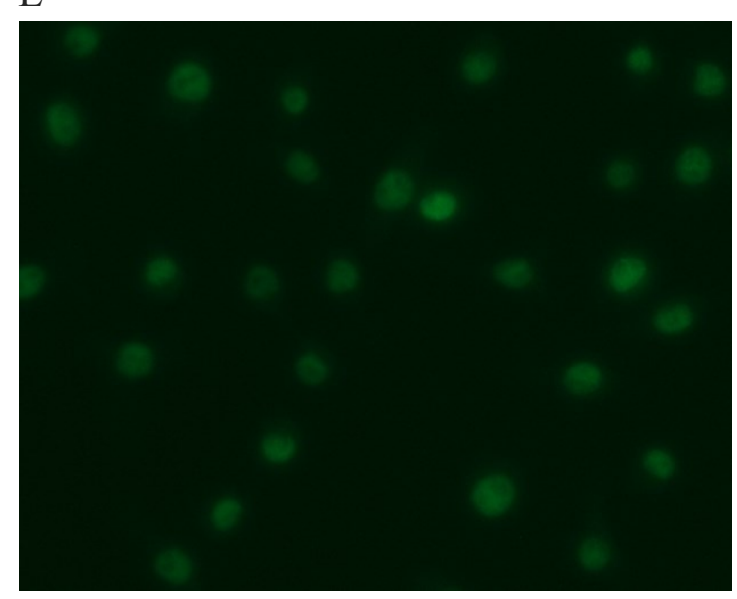

Saline-Wave2

Figure 12: Immunofluorescence staining of BV-2 microglia for NF-kB. The quantity analysis representing the corrected cell fluorescence intensity was calculated using the Image $\mathrm{J}$ (1.46r) software as follows: [(Integrated Density/ Area) - Adjusted Background]. There was no significant difference noticed in NF-kB signaling among these four groups. 


\section{Discussion:}

Microglia have an active and important role in neuronal damage and protection since they are responsible for neuronal development and maintenance. Activated microglia have been involved not only in infection and inflammation, but many CNS diseases such as pain, neurodegeneration, brain trauma, and stroke (Baron, 2006; Aravalli et al., 2007; Mao et al., 2012; Tsuda et al., 2012). Previous studies have shown that chronic inflammation is a major characteristic feature of Parkinson's disease (Sulzer, 2007; Trang et al., 2012; Herrero et al., 2015; Kaur et al., 2018). Chronic activation of microglia as happens in PD can induce severe neuronal damages as microglia once activated, release many pro-inflammatory mediators such IL-1, TNF, NO, and ROS (Trang et al., 2012). Since all eukaryotic cells need to reorganize their actin cytoskeleton in order to divide, change shape, move and take up nutrients for survival, the changes in microglial shape and form upon activation, also depend upon the actin cytoskeleton reorganization. WASP and WAVE proteins are the fundamental reorganizers of the actin-cytoskeleton (Kurisu \& Takenawa, 2009). They are required for the activation of the Arp2/3 complex, the activation of this complex leads to rapid actin polymerization (Kurisu \& Takenawa, 2009). Actin polymerization which forms new actin filament is a critical step for many cellular processes such as cell motility, phagocytosis, endocytosis (Takenawa et al., 2009). Microglial activation and function as primary scavenging and phagocytic cells of CNS require proper rearrangement of the actin cytoskeleton. WASP family Verproline homology protein 2 (WAVE2) which are the fundamental regulator of the actin cytoskeleton, and primarily expressed in hematopoietic cells, are essential for the formation of various cellular processes and projections in microglia. The previous study has also 
found WAVE2 as a potential genetic interactor of LRRK2 (Kim et al., 20018). A recent study has suggested that the phagocytic response of microglia, macrophage, and other myeloid cells are regulated by LRRK2, with the help of specific modulation of the actincytoskeleton regulator, WAVE2 (Kim et al., 2018). LRRK2 mutations are not only the most common cause of familial PD, but are also associated with $10 \%$ of sporadic cases of PD (Correia et al., 2010).

In our present study, we have investigated the effect of WAVE 2 protein in BV-2 microglial cells after LPS stimulation. We have speculated that WAVE2 knock-down virus may blunt inflammatory phenotype of BV-2 microglial cells after LPS stimulation. Surprisingly, our results were in contrast to our speculation. In the first part of this study, we have shown the effects of LPS activation of BV-2 microglial cells in terms of morphological changes in BV-2 cells, oxidative stress and signaling of the proinflammatory transcription factor, NF-kB. Nuclear-factor kappa-B plays a wellcharacterized role in the regulation of cytokine production from immune cells. Endotoxin LPS activates BV-2 microglia through TLR4 and transcription factor NF-kB signaling pathways and promotes the release of proinflammatory cytokine (Dai, Li, Yu, Chen, \& Zhang., 2015). Our findings are consistent with the previous studies and confirm that LPS stimulation of BV-2 microglial cells result in upregulation of oxidative stress and NF-kB signaling (Kaneko et al., 2012; Dai et al., 2015). LPS treated BV-2 microglial cells appear round with few cellular processes as compared to untreated cells. It represents the typical active phagocytic form of activated and reactive microglia.

Our second experiment was focused on finding how this inflammatory phenotype of activated BV-2 microglial cells will be changed or affected by WAVE2 knock-down. 
We used the adeno-associated virus (AAV) as a vector for the delivery of WAVE2 siRNA into BV-2 cells. Western blot analysis confirms that we were able to reduce the expression of WAVE2 protein in BV-2 microglial cells as compared to control. WAVE2 siRNA did not completely block the expression of WAVE2 protein, which could indicate that our siRNA expression level was too low, duration of infection was insufficient for complete WAVE2 turnover, or, that the level of mRNA binding was not sufficient to cause complete removal of the WAVE2 protein. We infected BV-2 cells with AAV-WAVE2 siRNA for 24 hours before treating these cells with LPS. The previous study which was done using WAVE2siRNA adeno-associated virus vector to inhibit WAVE2 expression in mice SNC using the stereotaxic technique for the direct delivery of WAVE2 siRNA, also showed the WAVE2 expression was not completely ablated by this virus (Kim et al., 2018). Literature has shown that WAVE2 knocking down in LRRK2 G2019S KI mice and BMDMs, reduce the hyper-phagocytic activity to wild type level, which suggests that LRRK2 G2019S mediated increase in phagocytic activity is regulated by an increase in WAVE2 protein (Kim et al., 2018).

Our results have not shown any significant effect of WAVE2 knocking-down on the inflammatory phenotype of BV-2 microglial cells which we analyzed in terms of oxidative stress, morphological changes and NF-kB signaling, both in WAVE2 knockeddown and control BV-2 microglial cells. Only significant treatment (LPS) effect was observed in terms of increased CellRox uptake by LPS treated BV-2 cells and changes in the shape and form of BV-2 cells, which affirm the results of our first experiment. 
Interestingly, in contrast to our first experiment, when analyzed NF-kB signaling both in LPS treated WAVE2 knock-down cells and untreated cells, no significant treatment effect was observed in LPS treated BV-2 cells as compared of control, regardless of WAVE2 inhibition. There could be many factors that may have contributed to the outcomes that we haven't expected, such as the number of viral particles require to infect each cell, the duration of exposure to the virus, and exposure to air during the experiment. Increasing the viral titer and exposure time of BV-2 cells to WAVE2 siRNA AAV may provide different results.

Research on exploring the WAVE2 pathway in regulating cytoskeleton remodeling and phagocytosis and its role in the neuroinflammation associated with neurodegenerative disorders is growing. We also cannot ignore the significant role of LRRK2 and WAVE2 in the innate immune response associated with neuroinflammation. LRRK2-WAVE2 pathway has proven to be critical for the phagocytosis in microglia. The recent research has shown that LRRK2 knock-down decreases the expression of WAVE2 protein in BV-2 microglial cells, in primary microglia and BMDMs from LRRK2 KO mice (Kim et al., 2018). LRRK2 G2019S KI mice show an increase in WAVE2 protein (Kim et al., 2018). LRRK2 G2019S mutation enhances the phagocytosis response in microglia as evident by the increase in uptake of latex bead or E-coli particles (Kim et al., 2018). This enhanced phagocytosis response was prevented in LRRK2 G2019S KI mice when WAVE2 expression was inhibited by WAVE2 shRNA. This suggests that LRRK2 is required for regulating phagocytic activity via WAVE2, and G2019S mutation enhanced this action. The LRRK2-WAVE2 pathway may define an important role for altered immune response in PD. 
The findings presented in this study demonstrate that though WAVE2 inhibition has no obvious effect on BV-2 microglial inflammatory phenotype, further research is required to explore other inflammatory changes after inhibiting WAVE2 expression. We could investigate the expression of pro-inflammatory mediators and cytokines after BV-2 microglial stimulation with endotoxin, LPS. Another aspect that might be interesting to explore, is the individual actin protein, filamentous versus globular actin, which is required for the actin polymerization and formation of cellular processes. LRRK2-WAVE2 pathway could be the potential therapeutic target in combating the neuroinflammation associated with the Parkinson's disease. 


\section{References}

Akira, S., Uematsu, S., Takeuchi, O. (2006). Pathogen recognition and innate immunity. Cell 124(4). 783-801. doi: 10.1016/j.cell.2006.02.015

Aravalli, R. N., Peterson, P. K., Lokensgard, J. R. (2007). Toll-like receptors in defense and damage of the central nervous system. J Neuroimmune Pharm, 2. 297-312

Blasi, E., Barluzzi, R., Bochchini, V., Mazzolla, R., \& Bistoni, F. (1990). Immortalization of murine microglial cells by a v-raf/v-myc carrying retrovirus. Journal of Neuroimmunology,27(2-3). 229-237. PMID:2110186

Bonifati, V., Rizzu, P., Van Baren, M. J., Schaap, O., Breedveld, G.J............ and Krieger, E. (2003). Mutation in the DJ-1 gene associated with autosomal recessive early onset parkinsonism. Science, 299(5604). 256-259. doi: 10.1126/science.1077209

Baron, R. (2006). Mechanism of disease: Neuropathic pain- A clinical perspective. Nature Clinical Practical Neurology, 2(2). 95-106. doi: 10.1038/ncpneuro0113

Bonomini, F., Tengattini, S., Fabiano, A., Bianchi, R., \& Rezzani, R. (2008). Atherosclerosis and Oxidative stress. Histology and Histopathology, 23(3). 381390. doi: 10.14670/HH-23.381

Bendor, J.T., Logan, T.P., Edwards, R.H. (2013). The function of alpha-synuclein. Neuron, 79(6). 1044-1066. doi: 10.1016/j.neuron.2013.09.004

Cheng, C., Ulane, M., \& Burke, R. (2010). Clinical progression in Parkinson's disease and the Neurobiology of axons. Ann. Neurology, 67(6). 715-725. doi: 10.1002/ana.21995

Correia, G. L., Ferreira, J. J., Rosa, M., Coelho, M., Bonifati, V., and Sampaio, C. (2010). Worldwide frequency of G2019S LRRK2 mutation in Parkinson's disease: A systemic review. Parkinsonism Related Disorder, 16(4). 237-241. doi: 10.1016/j.parkreldis.2009.11.004

Dauer, W. and Przedborski, S. (2003). Parkinson's disease: mechanisms and models. Neuron 39, 889-909. doi: 10.1016/S0896-6273903000568-3

De Lau, L.M.L., \& Breteler, M.M.B. (2006). Epidemiology of Parkinson's disease. Lancet Neurology 5(6). 525-535. doi: 10.1016/S1474-4422(06)70471-9

DeLong, M. R. and Wichmann, T. (2007). Circuits and Circuit Disorders of the Basal Ganglia. Arch Neurology, 64(1). 20-24. doi: 10.1001/archneur.64.1.20

Dai, X., Li, N., Chen, Z., Hua, R., Qin, X., and Zhan, Y. (2014). Activation of BV2 Microglial cells by LPS triggers an inflammatory reaction in PC12 cell apoptosis 
through a toll-like receptor 4-dependent pathway. Cell Stress Chaperones, 20(2). 321-331. doi: 10.1007/s12192-014-0552-1

Fan, C. H., Lin, C. Y., Liu, H. L., \& Yeh, C. K. (2017). Ultrasound targeted CNS gene delivery for Parkinson's disease treatment. Journal of Controlled Release, 261.

246-262. doi: 10.1016/j.jconrel.2017.07.004

Graeber, M. B. (2010). Changing face of microglia. Science 330(6005). 783-788. doi: 10.1126/science.1190929

Grimes, D., Gordon, J., Snelgrove, B., Martin, W., Wieler, M., ................., \& Jog, M. (2012). Canadian guidelines on Parkinson's disease introduction. Canadian Journal of Neurological Sciences, 39(4). S1-30. PMID: 23126020

Gillardon, F., Schmid, R., \& Draheim, H. (2012). Parkinson's disease-linked LRRK2 $(\mathrm{R} 1441 \mathrm{G})$ Mutation increases pro-inflammatory cytokines release from activated microglial cells and resultant neurotoxicity. Neuroscience, 208. 41-48. doi: 10.1016/j.neuroscience.2012.02.001

Gelb, D.J., Oliver, E., \& Gilman, S. (1999). Diagnostic criteria for Parkinson's disease. Archeology Neurology, 56(1). 33-39. doi: 10.1001/archneur.56.1.33

Han, B. S., Lacovitti, L., Katano, T., Hattori, N., Seol, W., \& Kim, K. S. (2008). Expression of the LRRK2 gene in the midbrain dopaminergic neurons of the substantia nigra. Neuroscience Lette, 442. 190-194. doi: 10.1016/j.neulet.2008.06.086

Henchcliffe, C., \& Beal, M.F. (2008). Mitochondrial biology and oxidative stress in Parkinson's Disease pathogenesis. Nature Clinical Practical Neurology, 4(11). 600-609. doi: 10.1038/ncpneuro0924

Healy, D., Falchi, M., O’Sullivan, S., Bonifati, V., Durr, A., Bressman, S., ................, \& Wood, N. (2008). Phenotype, genotype and worldwide genetic penetrance of LRRK2 Associated Parkinson's disease: a case control study. Lancet Neurology, 7. 583-590. doi: 10.1016/s1474-4422(08)70117-0

Henn, A., Lund, S., Hedtjarn, M., Schrattenholz, A., Porzgen, P., \& Leist, M. (2009). The Suitability of BV2 cells as alternative model system for primary microglia cultures or for animal experiments examining brain inflammation. ALTEX, 26(2). 83-94. PMID: 19565166

Herrero, M. T., Estrada, C., Maatouk, L., and Vyas, S. (2015). Inflammation in Parkinson's disease: role of glucocorticoids. Frontiers in Neuroanatomy, 9(32). doi: 10.3389/fnana.2015.00032

Hirsch, L., Jette, N., Frolkis, A., Steeves, T., \& Pringshein, T. (2016). The incidence of Parkinson's disease: a systematic review and meta-analysis. Neuroepidemiology,46. (292-300). doi: 10.1159/000445751 
Kitada, T., Asakawa, S., Hattori, N., Matsumine, H., Yamamura, Y., Minoshima, S. (1998). Mutation in the parkin gene cause autosomal recessive juvenile parkinsonism. Nature, 392(6676). 605-608. doi: 10.1038/33416

Kaltschmidt B, Ndiaye D, Korte M. (2006). NF-kappaB regulates spatial formation and synaptic plasticity through protein kinase A/CREB signaling. Molecular Cell Biology, 26(8).2936- 2946. doi: 10.1128/MCB.26.8.2936-2946.2006

Kurisu, S., and Takenawa, T. (2009). The WASP and WAVE family proteins. Genome Biology, 10(226). https://doi.org/10.1186/gb-2009-10-6-226

Kilarski, L. L., Pearson, J. P., Newsway, V., Majounie, E., Knipe, M. D. W., \& Misbahuddin, A. (2012). Systemic review and UK-based study of PARK2 (parkin), PINK1, PARK7 (DJ-1) and LRRK2 in early onset Parkinson's Disease. Movement Disorders, 27(12). 1522-1529. doi:10.1002/mds.25132

Kaneko, Y. S., Ota, A., Nakashima, A., Mori, K., and Nagatsu, T. (2012). Regulation of oxidative stress in long-live lipopolysaccharide-activated microglia. Clinical and Experimental Pharmacology and Physiology, 39. 599-607. doi: 10.11111/j.14401681.2012.05716.x

Kaur, R., Mehan, S., \& Singh, S. (2018). Understanding multifactorial architecture of Parkinson's disease: pathophysiology to management. Neurological Sciences, 40(1). 13-23. doi: 10.1007/s10072-018-3585-x

Lee, S. J. and Lee, S. (2002). Toll-like receptors and inflammation in the CNS. Current Drug Targets- Inflammation and Allergy, 1(2). 181-191. doi: $10.2174 / 1568010023344698$

Lehnardt, S., Massillon, L., Follett, P. (2003). Activation of innate immunity in the CNS triggers neurodegeneration through a toll-like receptor 4-dependent pathway. Proc Natural Academy of Science USA, 100(14). 8514-8519. doi: 10.1073/pnas. 1432609100

Lesage, S., \& Brice, A. (2012). Role of mendelian gene in "sporadic" Parkinson's disease. Parkinson's and Related Disorder, 18, S66-S70. doi: 10.1016/S1353 8020(11)70022-0

Listwak, S. J., Rathore, P. Herkenham, M. (2013). Minimal NF-kB activity in neurons. Neuroscience, 250. 282-299. doi: 10.1016/j.neuroscience.2013.07.013

Lill, M.C. (2016). Genetics of Parkinson's disease. Molecular and Cellular Probes, 30(6). 386-396. doi: 10.1016/j.mcp.2016.11.001

Miki, H., Suetsugu, S., and Takenawa, T. (1998). WAVE, a novel WASP-family protein involved in actin reorganization induced by Rac. EMBO J,17(23). 6932-6941. doi: 10.1093/emboj/17.23.6932 
Machesky, L. M., and Insall, R. H. (1998). Scar 1 and the related Wiskott-Aldrich syndrome protein, WASP, regulating the actin cytoskeleton through the Arp2/3 complex. Current Biology, 8(25). 1347-1356. PMID: 9889097

McCarthy, S., Somayajulu, M., Sikorska, M., Borowy-Borowski, H., \& Pandey, S. (2004).

Paraquat induces oxidative stress and neuronal cell death; Neuroprotection by water-soluble Coenzyme Q. Science Direct, Toxicology and Applied Pharmacology, 201(1). 21-31. doi: 10.1016/j.taap.2004.04.019

Marin, I. (2006). The Parkinson's disease gene LRRK2: evolutionary and structural insight. Molecular Biology Evol, 23. 2423-2433.

Moehle, M. S., Webber, P. J., Tse, T., Sukar, N., Standaert, D. J., DeSilva, T. M., Cowell, R. M., \& West, A. B. (2012). LRRK2 inhibition attenuates microglial inflammatory responses. Journal of Neuroscience, 321. 1602-1611.

Mhyre, T., Boyd, J., Hamill, R., \& Maguire-Zeiss, K. (2012). Parkinson's Disease. Subcell Biochem, 65: (386-455). doi:10.1007/978-94-007-5416-4_16

Mao, S. S., Hua, R., Zhao, X. P. (2012). Exogenous administration of PACAP alleviate Traumatic brain injury in rats through a mechanism involving TLR4/MyD88/NFkB pathway. J Neurotrauma, 29(10). 1941-1959. doi: 10.1089/neu.2011.2244

Marcogliese, P., (2017). LRRK2 (I2010T) functional genetic interactors that modify eye degeneration and dopaminergic cell loss in Drosophila. Human Molecular Genetics, 26. 1247-1257.

Polymeropoulos, M.H., Levadan, C., Leroy, E., Ide, S.E., .................. Dutra, L. (1997). Mutations in the alpha-synuclein gene identified in families with Parkinson's disease. Science, 276(5321). 2045-2047.

Rietschel, E. T., Kirikae, T., Schade, F., Mamat, U., Schmidt, G., Loppnow, H., Ulmer, A., Zahringer, U., and Padova, F., (1994). Bacterial endotoxin: molecular relationships of structure to activity and function. The FASEB Journal. doi:10.1096/fasebj.8.2.8119492

Reicher, B., Perl, Orly., Matalon, O., \& Barda-Saad, M. (2012). WASp and WAVE protein: From structure, through function, to clinical aspects. Journal of Clinical\& Cellular Immunology, S12. doi:

Russo, I., Barlati, S., \& Bossetti, F. (2011). Effects of neuroinflammation on regenerative capacity of brain stem cells. Journal of Neurochemistry, 116. 947-956. doi:

Rideout, H. J., and Stefanis, L. (2014). The neurobiology of LRRK2 and its role in the Pathogenesis of Parkinson's disease. Neurochem Res, 39(3). 576-592. doi: 10.1007/s1 1064-013-1073-5 
Russo, I., Bubacco, L., \& Greggio, E. (2014). LRRK2 and neuroinflammation: partners in crime in Parkinson's disease? Journal of neuroinflammation, $11(52)$. http://www.jneuroinflammation.com/content/11/1/52

Reeve, A., Simcox, E., \& Turbull, D. (2014). Ageing and Parkinson's disease: why is advancing age is the biggest risk factor? Ageing Res Rev 14. (19-30). doi: 10.1016/j.arr.2014.01.004

Spillanitini, M.G., Schmidt, M.L., Lee, V.M., Trojanowski, J.Q., Jakes, R., \& Goedert, M. (1997). Alpha-synuclein in Lewy bodies. Nature,388(6645). 839-840.

Schrag, A., Horsfall, L., Walters, K., Noyce, A., \& Peterson, I. (2015). Prediagnostic presentation of Parkinson's disease I primary care: a case control study. Lancet Neurology, 14(1). 57-64. Doi: 10.1016/S1474-4422(14)70287-

M, Srinivasan., and D. K., Lahiri. (2015). Significance of NF-kB as pivotal therapeutic target in the neurodegenerative pathologies of Alzheimer's disease and multiple sclerosis. Expert Opinion Therapeutic Targets, 19(4). 471-487. doi:10.1517/14728222.2014.989834

Tak, P. P., and Firestein, G. S. (2001). NF-kB: a key role in inflammatory diseases. The Journal of Clinical Investigation, 107(1). 7-11. https://doi.org/10.1172/JCI11830

Tsuda, M., Tozaki-Saiton, H., Inou, K. (2012). Purinergic system, microglia and neuropathic pain. Current Opinion Pharmacology, 12. 74-79.

Trinh, J. and Farrer, M. (2013). Advances in the genetics of Parkinson's disease. Nature Review Neurology, 9(8). 445-454. doi: 10.1038/nrneurol.2013.132

Uttara, B., Singh, A., Zamboni, P., \& Mahajan, R. (2009). Oxidative stress and neurodegeneration diseases: A review of upstream and downstream antioxidant therapeutic options. Current Neuropharmacology,7(1). 65-74. doi: $10.2174 / 157015909787602823$

Valente, E. M., Abou-Suleiman, P. M., Caputo, O., Muqit, M. M. K., Harvey, K., and Gispert, S. (2004). Hereditary early-onset Parkinson's disease caused by mutation in PINK1. Science, 304(5674). 1158-1160. doi: 10.1126/science.1096284

Villarino-Guell, C., Wider, C., Ross, O., Dachsel, J., .................., \& Lincoln, S. (2011). VPS35 mutations in Parkinson's disease. American Journal of Human Genetics, 89(1). 162-167. doi: 10.1016/j.ajhg.2011.06.001

Wu, D. C., Re. D. B., Nagai, M. et al. (2006). The inflammatory NADPH oxidase enzyme modulates motor neuron degeneration in ALS mice. Proc. Natl. Acad. Sci. USA, 103(32). 12132-12137. doi: 10.1073/pnas.0603670103

Xiao-jing, D., Na, L., Le, Y., Zi-yang, C., ................. \& Yong-Mei, Z. (2014). Activation of BV2 microglia by LPS triggers an inflammatory reaction in PC12 
cell apoptosis through toll-like receptor 4-dependent pathway. Cell Stress and Chaperones 20. 321-331. doi: 10.1007/s12192-014-0552-1

Zimprich, A., Biskup, S., Leitner, P., Farrer, M., Lincoln, S., .................. Gasser, T. (2004). Mutations in LRRK2 cause Autosomal Dominant Parkinsonism with pleomorphic pathology. Neuron, 44(4). 601-607. doi:

10.1016/j.neuron.2004.11.005 